INSTITUTO DE PESQUISAS ENERGÉTICAS E NUCLEARES

Autarquia associada à Universidade de São Paulo

\title{
AVALIAÇÃO DAS DOSES RESULTANTES DE PROCEDIMENTOS RADIODIAGNÓSTICOS REALIZADOS EM MEDICINA VETERINÁRIA E AVALIAÇÃO DAS DOSES SECUNDÁRIAS DE RADIAÇÃO ESPALHADA NO CORPO CLÍNICO E NOS PROPRIETÁRIOS DOS ANIMAIS
}

\section{GLAUCO ROGÉRIO VENEZIANI}

Dissertação apresentada como parte dos requisitos para obtenção do Grau de Mestre em Ciências na Área de Tecnologia Nuclear - Aplicações

Orientadora:

Dra. Letícia Lucente Campos Rodrigues

Versão corrigida

Versão original se encontra disponível no IPEN

São Paulo 


\section{AGRADECIMENTOS}

À minha orientadora, Dra. Letícia L. C. Rodrigues pela oportunidade de crescimento que me proporcionou durante a orientação do mestrado, confiança, estímulo e amizade.

Ao IPEN, na pessoa do Sr. Superintendente Dr. José Carlos Bressiani, pela oportunidade de executar este trabalho.

À Comissão Nacional de Energia Nuclear (CNEN), pela bolsa de mestrado.

À Dra. Linda V. E. Caldas pelo apoio durante a realização deste trabalho.

Aos meus pais, José Omir e Neusa, pelo apoio incondicional, incentivo e afeto.

À todos do LC I - IPEN pela ajuda, companheirismo e paciência.

Ao Hospital Veterinário Dr. Halim Atique de São José do Rio Preto.

Aos meus irmãos, pelo grande incentivo e carinho.

Ao meu amor, pela ajuda em todos os momentos. 


\title{
AVALIAÇÃO DAS DOSES RESULTANTES DE PROCEDIMENTOS RADIODIAGNÓSTICOS REALIZADOS EM MEDICINA VETERINÁRIA E AVALIAÇÃO DAS DOSES SECUNDÁRIAS DE RADIAÇÃO ESPALHADA NO CORPO CLÍNICO E NOS PROPRIETÁRIOS DOS ANIMAIS
}

\author{
Glauco Rogério Veneziani
}

\section{RESUMO}

O objetivo primordial em radiologia veterinária é a produção de radiografias com qualidade diagnóstica, em uma primeira tentativa. Esse objetivo deve atender a três propósitos: (1) diminuir a exposição à radiação do paciente e trabalhadores; (2) diminuir o custo do estudo para o cliente e (3) produzir dados diagnósticos para rápida interpretação e tratamento do paciente.

Esse trabalho teve por objetivo a determinação das doses em cães submetidos a radiografias de tórax e abdômen utilizando a técnica da dosimetria termoluminescente (TL). As doses de radiação foram avaliadas com a utilização de dosímetros termoluminescentes de sulfato de cálcio dopado com disprósio $\left(\mathrm{CaSO}_{4}\right.$ :Dy) e fluoreto de lítio dopado com magnésio e titânio ( $\mathrm{LiF}: \mathrm{Mg}, \mathrm{Ti}$ ). Os resultados obtidos indicam que é extremamente importante a avaliação das doses de radiação envolvidas em procedimentos diagnósticos de radiologia veterinária, para a avaliação das doses nos animais e para ser usado como um parâmetro para a monitoração individual dos proprietários de animais, que auxiliam no posicionamento, e para a proteção dos trabalhadores ocupacionalmente expostos nas Clínicas de Radiologia Veterinária. 


\title{
EVALUATION OF DOSES FROM RADIODIAGNOTIC PROCEDURES PERFORMED IN VETERINARY MEDICINE AND ASSESSING OF THE DOSES OF SECONDARY RADIATION IN THE MEDICAL STAFF AND ANIMAL OWNERS
}

\author{
Glauco Rogério Veneziani
}

\begin{abstract}
The primary goal in veterinary radiography is to produce radiographs of diagnostic quality on the first attempt. This goal serves three purposes: (1) to decrease radiation exposure to the patient and veterinary personnel; (2) to decrease the cost of the study for the client; and (3) to produce diagnostic data for rapid interpretation and treatment of the patient.

This work aimed to determine the doses in dogs submitted to chest and abdomen Xrays using the technique of thermoluminescence (TL) dosimetry. The radiation doses were assessed using thermoluminescent dosimeters of calcium sulphate doped with dysprosium $\left(\mathrm{CaSO}_{4}: \mathrm{Dy}\right)$ and lithium fluoride doped with magnesium and titanium (LiF:Mg,Ti). The obtained results indicate that is extremely important the assessment of radiation doses involved in veterinary diagnostic radiology procedures, to evaluate the delivered doses to the animals, to be used as a parameter in the individual monitoring of pet's owners, who assist the animal positioning, and to protect occupationally exposed workers at the Veterinary Radiology Clinics.
\end{abstract}




\section{Sumário}

1. INTRODUÇÃ

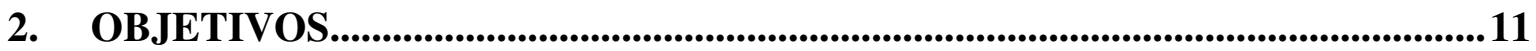

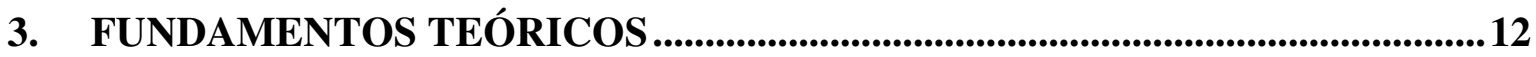

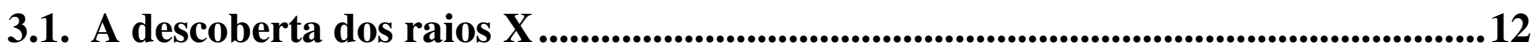

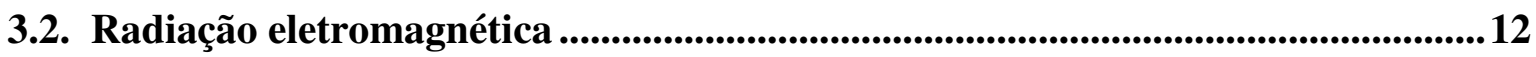

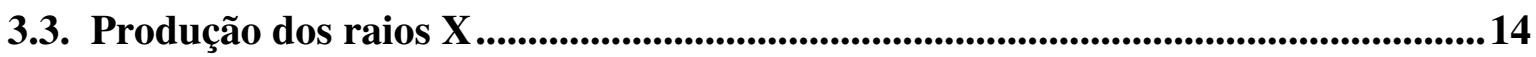

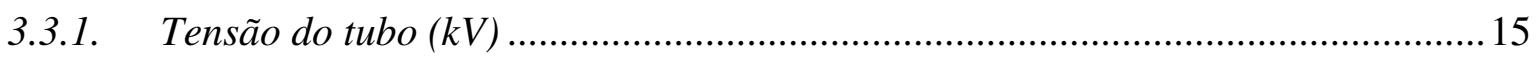

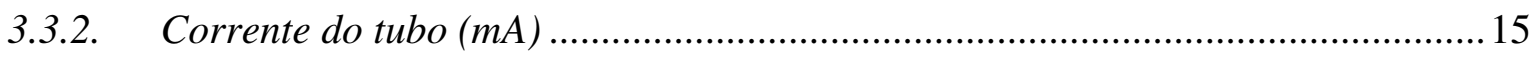

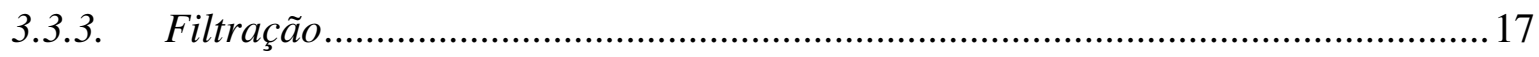

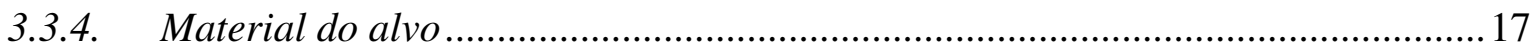

3.4. Interação da radiação com a matéria ................................................................17

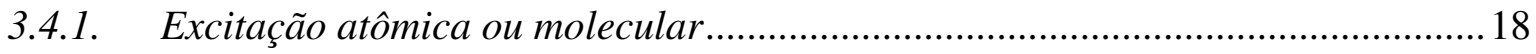

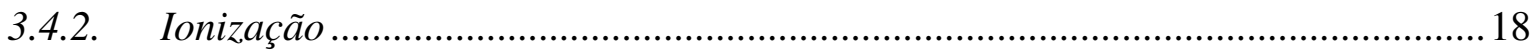

3.4.3. Radiações diretamente e indiretamente ionizantes ............................................. 18

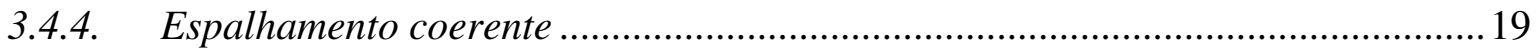

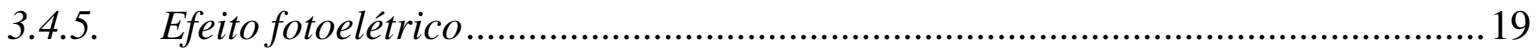

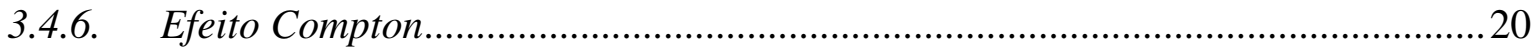

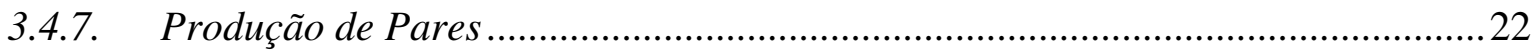

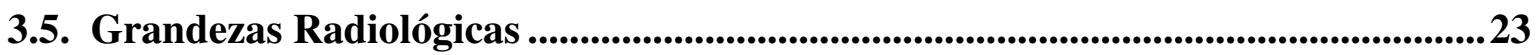

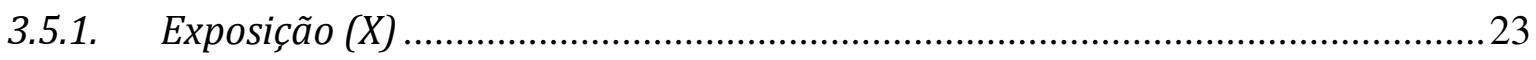

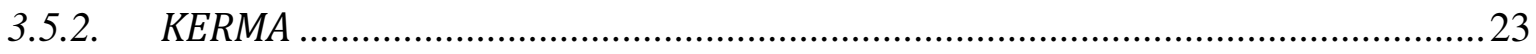

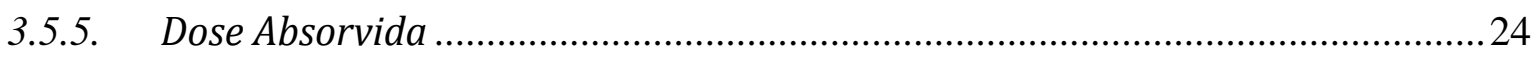

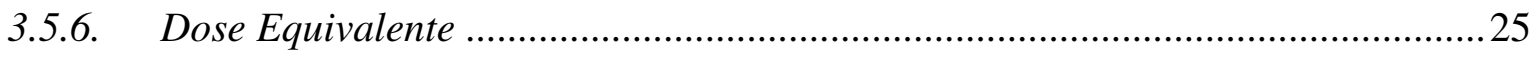

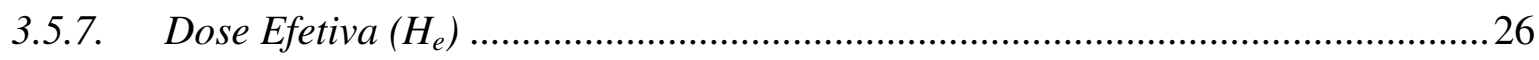


3.6. História da Dosimetria Termoluminescente........................................................27

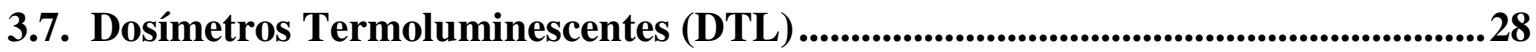

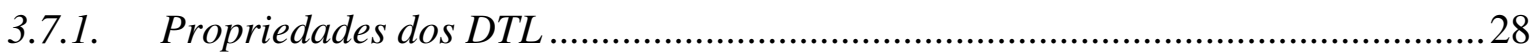

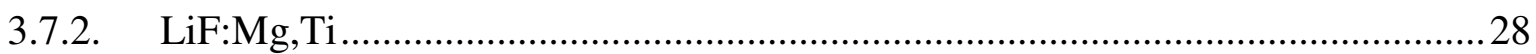

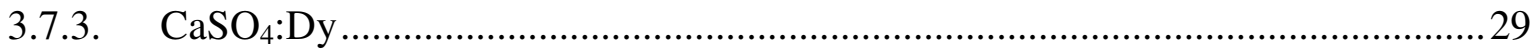

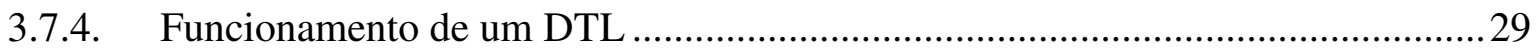

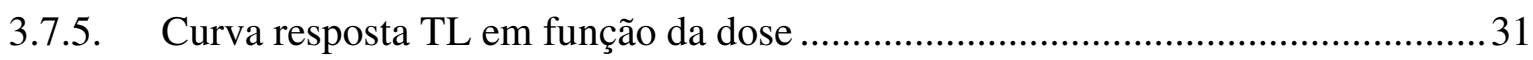

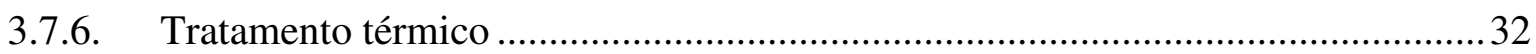

3.8. Dosimetria na Radiologia Veterinária ...............................................................................32

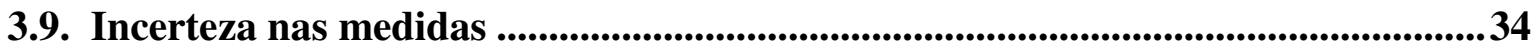

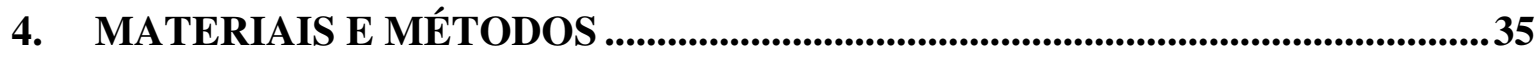

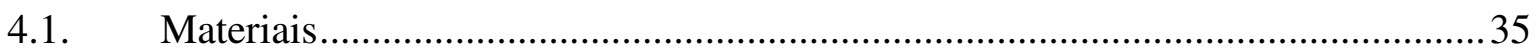

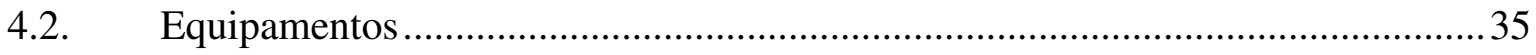

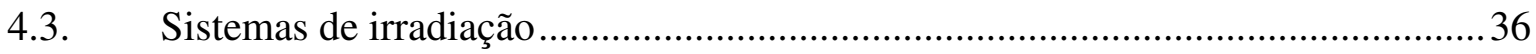

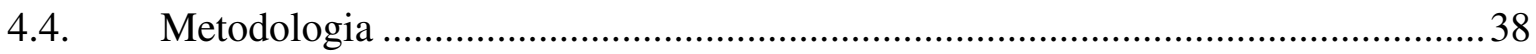

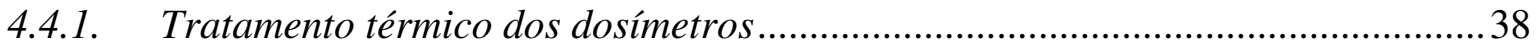

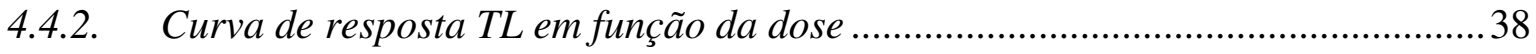

4.4.3. Aquisição dos dados e irradiação dos dosímetros................................................... 39

4.4.4. Análise da radiação espalhada no ambiente e da dose individual dos indivíduos

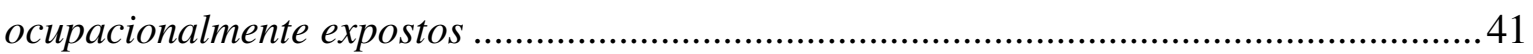

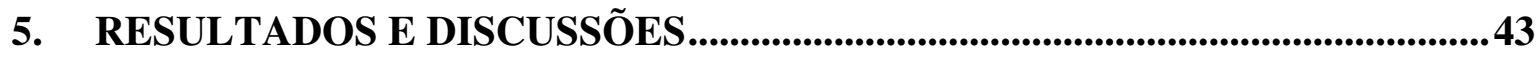

5.1. Curvas de resposta TL em função da dose e equações de ajustes ..................43

5.2. Dose em animais submetidos a exame de abdômen ....................................... 46

5.3. Dose em animais submetidos a exames de tórax ..........................................50

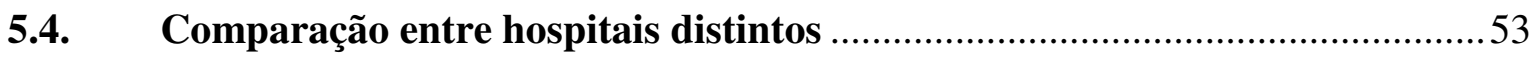

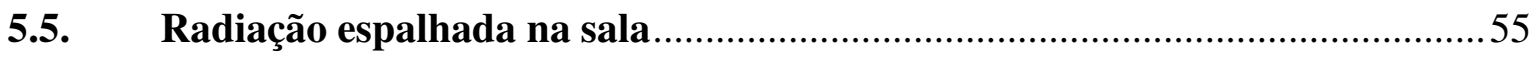


5.6. Doses individuais recebidas por trabalhadores e estagiários ..........................56

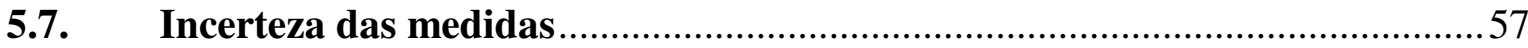

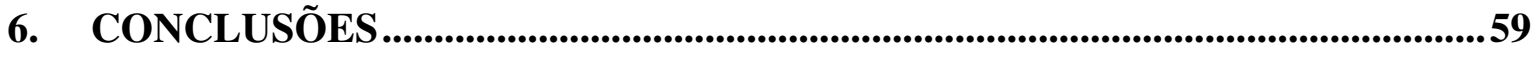

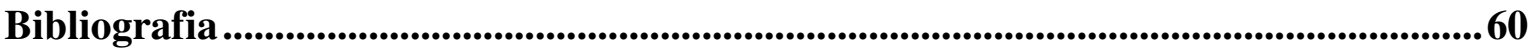

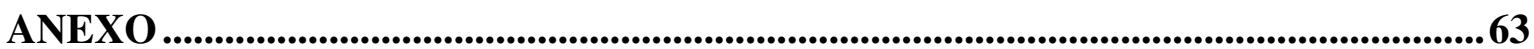




\section{INTRODUÇÃO}

Os raios $\mathrm{X}$ foram descobertos em 8 de novembro de 1895 por Wilhelm Conrad Roentgen, um físico alemão. Estes novos "raios" rapidamente passaram a ser usados na medicina e, em pouco tempo, muitas aplicações médicas sofisticadas foram inventadas. A descoberta dos raios $\mathrm{X}$ revolucionou o diagnóstico e o tratamento de doenças no homem e em animais. Embora os raios X sejam valiosos à Medicina, sua interação com o tecido gera ionização, o que pode causar danos biológicos significativos. Uma vez que os raios X são amplamente aplicados, mesmo sendo potencialmente prejudiciais, então seus princípios básicos devem ser entendidos (THRALL, 2010).

Os princípios básicos de radioproteção são três: a justificação da prática, a otimização da proteção radiológica e a limitação das doses individuais.

A justificação é o princípio básico de proteção radiológica, que estabelece que nenhuma prática ou fonte adstrita a uma prática deve ser autorizada a menos que produza suficiente benefício para o indivíduo exposto ou para a sociedade, de modo a compensar o detrimento que possa ser causado.

O princípio de otimização estabelece que as instalações e as práticas devem ser planejadas, implantadas e executadas de modo que a magnitude das doses individuais, o número de pessoas expostas e a probabilidade de exposições acidentais sejam tão baixas quanto razoavelmente exequíveis (Princípio ALARA $=$ "as low as reasonably achievable"), levando-se em conta fatores sociais e econômicos, além das restrições de dose aplicáveis.

Os limites de doses individuais são valores de dose efetiva ou de dose equivalente, estabelecidos para exposição ocupacional e exposição do público decorrente de práticas controladas, cujas magnitudes não devem ser excedidas (CNEN NN 3.01, 2011; ANVISA, 1998; ICRP 103, 2007). Na tabela 1 são apresentados os limites de doses anuais estabelecidos pela norma NN 3.01 da CNEN. 
Tabela 1 - Limites anuais de dose estabelecidos pela Norma CNEN -NN-3.01

\begin{tabular}{cccc}
\hline \multicolumn{4}{c}{ Limites de Dose Anuais [a] } \\
\hline Grandeza & Órgão & $\begin{array}{c}\text { Indivíduo ocupacionalmente } \\
\text { exposto }\end{array}$ & Indivíduo do público \\
\hline Dose efetiva & Corpo inteiro & $20 \mathrm{mSv}[\mathrm{b}]$ & $1 \mathrm{mSv}[\mathrm{c}]$ \\
Cristalino & $20 \mathrm{mSv}[\mathrm{b}]$ & $15 \mathrm{mSv}$ \\
& Pele [d] & $500 \mathrm{mSv}$ & $50 \mathrm{mSv}$ \\
& Mãos e pés & $500 \mathrm{mSv}$ & --- \\
\hline
\end{tabular}

Fonte: CNEN-NN-3.01

[a] Para fins de controle administrativo efetuado pela $C N E N$, o termo dose anual deve ser considerado como dose no ano calendário, isto é, no período decorrente de janeiro a dezembro de cada ano.

[b] Média ponderada em 5 anos consecutivos, desde que não exceda $50 \mathrm{mSv}$ em qualquer ano.

[c] Em circunstâncias especiais, a CNEN poderá autorizar um valor de dose efetiva de até $5 \mathrm{mSv}$ em um ano, desde que a dose efetiva média em um período de 5 anos consecutivos, não exceda a $1 \mathrm{mSv}$ por ano.

[d] Valor médio em $1 \mathrm{~cm}^{2}$ de área, na região mais irradiada.

O órgão internacional que regulamenta a Proteção Radiológica em Medicina Veterinária é o Conselho Nacional de Radioproteção e Medidas (National Council on Radiation Protection and Measurements - NCRP). A norma NCRP Report $\mathrm{n}^{\circ} 148$ proporciona um guia para o desenvolvimento de um programa efetivo de segurança radiológica e recomendações para a utilização de equipamentos radiográficos, fluoroscópicos e terapêuticos em medicina veterinária. Estas recomendações são designadas para alcançar os seguintes objetivos de radioproteção: prevenir a ocorrência de danos significativos causados pela radiação e limitar o risco de efeitos estocásticos, tais como câncer e efeitos genéticos (NCRP Report 148, 2004).

Seifert e colaboradores publicaram trabalhos sobre a avaliação da exposição à radiação de proprietários de animais e pessoal do corpo clínico durante a realização de radiografias em pequenos animais, concluindo que os valores de dose avaliados estavam todos abaixo dos limites estabelecidos dentro dos padrões adotados na Alemanha, e que não se justifica que os proprietários recebam doses acima dos limites para indivíduos do público (SEIFERT et al., 2008; SEIFERT, 2007). 
A medicina veterinária diagnóstica, como todas as áreas de conhecimento humano, está em crescente evolução e negar seu uso e consequentes benefícios é manter-se no passado. Por outro lado, é essencial assegurar que as doses de radiação recebidas pelos trabalhadores ocupacionalmente expostos e indivíduos do público estejam dentro dos limites permissíveis. Do mesmo modo, é também importante evitar qualquer irradiação desnecessária para o paciente animal.

Embora as normas e medidas de radioproteção sejam designadas somente para os seres humanos, os fundamentos e elementos de proteção radiológica contidos nas normas da NCRP- report 148 são também aplicáveis às práticas de radiologia e oncologia na área de medicina veterinária. A análise de doses em diagnóstico por imagem em não-humanos é um setor da proteção radiológica pouco explorada pela comunidade científica nacional e internacional como, por exemplo, os efeitos biológicos causados por tais procedimentos. Embora a realização de exames radiográficos, tomografia computadorizada (TC) e até mesmo procedimentos radioterápicos representem um método prioritariamente utilizado para diagnóstico em humanos, essas técnicas vêm ganhando território no setor veterinário (GARLAND et al., 2002) e tem sido muito eficientes para determinar diversas doenças acometidas em animais. (GARLAND et al., 2002; FONSECA PINTO, 2007; NCRP,2004).

O mercado de animais domésticos atual tem grande importância não apenas para os proprietários, mas também para a economia como um todo. Na Europa e nos Estados Unidos, o percentual de donos que consideram seus bichos de estimação como familiares é de 30\%, já no Brasil esse índice é de 10\%, mas aponta para um crescimento acentuado. A população brasileira de cães e gatos é a segunda maior do mundo, com 48 milhões, perdendo apenas para os EUA com 170 milhões de animais. Em 2009 a indústria de produtos e serviços veterinários movimentou 69 bilhões de dólares no mundo todo. $\mathrm{O}$ Brasil está entre os seis maiores mercados mundiais, o setor teve faturamento de 9 bilhões de reais (VEJA, 2009). A expectativa para o ano de 2012 é que o faturamento anual apenas na grande São Paulo seja de 9 bilhões de reais (VEJA-SP, 2012).

Por esses motivos as pesquisas envolvendo animais domésticos se tornaram tão importantes e a tendência de crescimento na área de pesquisa para eles é cada vez mais promissora. 


\section{OBJETIVOS}

Este trabalho tem como objetivo a análise das doses de radiação envolvidas nos procedimentos de exames diagnósticos em medicina veterinária e a avaliação das doses secundárias de radiação espalhada no corpo clínico e nos proprietários dos animais; além de promover a familiarização com a técnica de dosimetria termoluminescente, acompanhamento e avaliação das doses em exames diagnósticos do tipo radiográficos e verificação do cumprimento das normas de proteção radiológica para os indivíduos do público e trabalhadores (indivíduos ocupacionalmente expostos).

Esse trabalho é de grande importância para o melhoramento do serviço de radiologia veterinária, fornecendo melhores condições e menor risco para os animais domésticos. 


\section{FUNDAMENTOS TEÓRICOS}

\subsection{A descoberta dos raios $X$}

Em 1895, Wilhelm Conrad Roentgen observou em seus experimentos que os raios emanados do tubo de Crookes tinham uma capacidade notável de atravessar diferentes materiais, desde livros, madeiras e placas metálicas com diversas espessuras. Durante a colocação de uma das peças entre o tubo e a tela, ele observou que o contorno dos ossos de seus dedos estava sendo mostrado na tela fluorescente. Concluiu que aqueles raios eram parcialmente parados pelos ossos, da mesma forma que por uma placa de vidro contendo átomos de chumbo. No dia 22 de dezembro de 1895, Roentgen chamou sua esposa e realizou uma radiografia da mão dela (OKUNO \& YOSHIMURA, 2010; MARTINS, 1998).

\subsection{Radiação eletromagnética}

Uma onda eletromagnética é constituída de campo elétrico e campo magnético oscilantes, perpendiculares entre si, que se propagam no vácuo com velocidade da luz $c=3 \times 10^{8} \mathrm{~m} \cdot \mathrm{s}^{-1}$. A radiação eletromagnética pode ser representada como um modelo de senoide (figura 1), que são caracterizadas por dois parâmetros: frequência e comprimento de onda (OKUNO \& YOSHIMURA, 2010; THRALL, 2010).

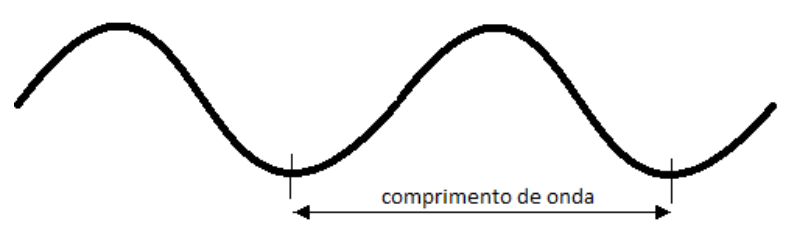

Figura 1 - O modelo senoide da radiação eletromagnética. A distância entre os picos é chamada de comprimento de onda.

Dependendo da frequência da onda eletromagnética, ela recebe denominações diferentes: micro-ondas, radiação infravermelha, luz visível, radiação ultravioleta e 
radiação gama (OKUNO \& YOSHIMURA, 2010). A figura 2 demonstra esse espectro eletromagnético.

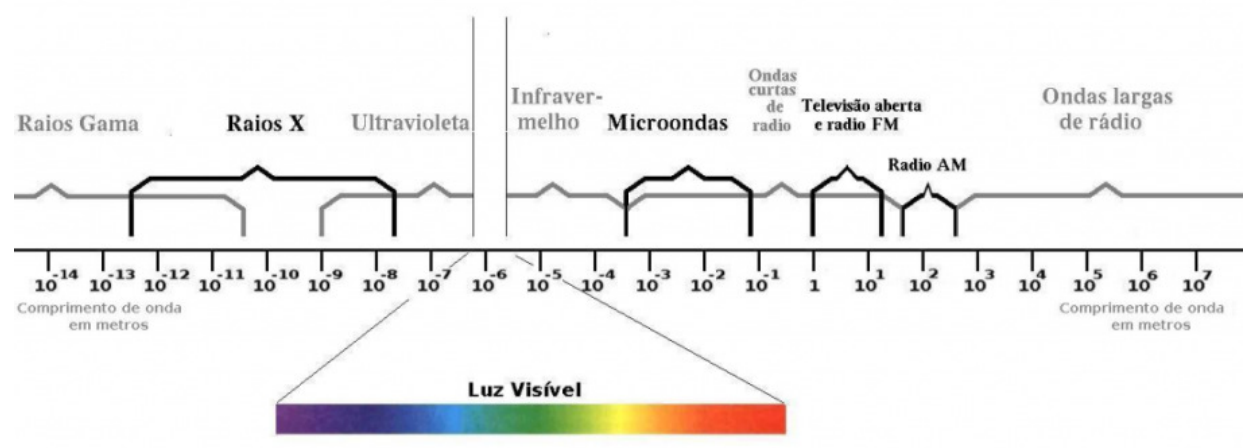

Figura 2 - Espectro da radiação eletromagnética.

Todo tipo de radiação eletromagnética trafega a velocidade da luz; a frequência, portanto, é inversamente proporcional ao comprimento de onda. A energia da radiação eletromagnética é relacionada ao comprimento de onda pela fórmula (equação 1) (THRALL, 2010).

$$
E=h \cdot \frac{c}{\lambda}
$$

Em que:

E é energia da radiação,

h é constante de Planck $\left(6,626068 \times 10^{-34} \mathrm{~m}^{2} . \mathrm{Kg} / \mathrm{s}\right)$,

c é a velocidade da luz $\left(3 \times 10^{8} \mathrm{~m} / \mathrm{s}\right)$,

$\lambda$ é o comprimento de onda.

A unidade de energia da radiação eletromagnética é o elétron volt $(\mathrm{eV})$. Um elétron-volt é a energia de um elétron acelerado por diferença de potencial de $1 \mathrm{~V}$. A radiação com energia maior do que $15 \mathrm{eV}\left(24,03 \times 10^{-19} \mathrm{~J}\right)$ já pode produzir ionização no interior das células. Os raios $\mathrm{X}$ usados para diagnóstico usam energias 1.000 vezes maiores; por isso, é importante entender os princípios dos raios $\mathrm{X}$ e como usá-los com segurança (THRALL, 2010).

A propriedade ionizante dos raios $X$ torna-os perigosos, uma vez que a interação desses com a matéria é um processo que se passa em nível atômico. Ao atravessarem um 
material, estas radiações transferem energia para as partículas que forem encontradas em sua trajetória. Caso a energia transferida seja superior à energia de ligação do elétron com o restante da estrutura atômica, este é ejetado de sua órbita. O átomo é momentaneamente transformado em um íon positivo. O elétron arrancado (íon negativo) desloca-se no meio, impulsionado pela energia cinética adquirida neste processo. Esta energia é dissipada através da interação do elétron com elétrons e núcleos de outros átomos, eventualmente encontrados em sua trajetória. Novos íons podem, assim, serem introduzidos na matéria. O processo é interrompido quando, tendo sua energia dissipada em interações (choques), os elétrons (e suas cargas negativas) acabam capturados por moléculas do meio. A introdução de pares de íons (positivo e negativo) na matéria recebe o nome de ionização (NOUAILHETAS, 2012).

Uma vez que o processo de ionização aconteça com o material genético de um ser vivo, esse está sujeito a sofrerem danos e/ou alterações que podem aumentar (1) a taxa de mutação; (2) a taxa de aborto ou anomalias; (3) a suscetibilidade a doenças, reduzindo a expectativa de vida. (4) o risco de desenvolvimento de câncer e (5) a formação de catarata (THRALL, 2010).

\subsection{Produção dos raios $X$}

Os raios X são produzidos por conversão de energia quando uma movimentação rápida de corrente de elétrons é subitamente desacelerada no alvo (anodo) de um tubo de raios $\mathrm{X}$, esse tubo é constituído de vidro contendo vácuo e dois eletrodos, esses eletrodos são projetados de modo que os elétrons produzidos no catodo (eletrodo negativo ou filamento) possam ser acelerados por diferença de potencial para o anodo (eletrodo positivo ou alvo). A figura 3 ilustra um tubo de raios $\mathrm{X}$ com alguns de seus componentes (CURRY et al., 1990).

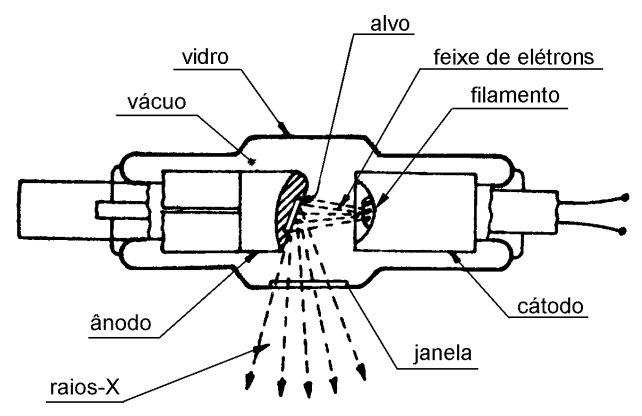

Figura 3 - Ilustração de um tubo de raios $X$ e seus componentes. 
O choque do feixe de elétrons com o alvo (anodo) produz dois tipos de raios X: raios $\mathrm{X}$ de freamento (apresentam espectro contínuo de energias) e raios $\mathrm{X}$ característicos (espectro de linhas ou raias, com energias bem definidas), a figura 4 mostra o espectro de emissão dos dois tipos de raios X (CURRY et al., 1990).

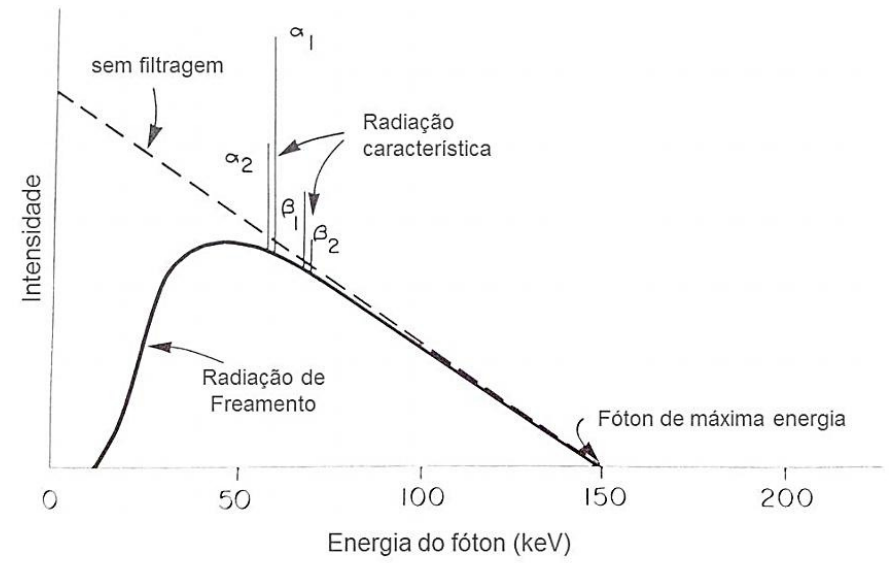

Figura 4 - Espectro da radiação de freamento e radiação característica.

A intensidade de um feixe de raios $\mathrm{X}$ é função do número total de fótons de raios $\mathrm{X}$ e da energia que os mesmos transportam, existem quatro grandezas das quais dependerão as intensidades do feixe de raios X: tensão do tubo, corrente do tubo, filtração e material do alvo (BITELLI, 2006).

\subsubsection{Tensão do tubo $(k V)$}

A energia dos fótons depende diretamente da energia dos elétrons que bombardeiam o alvo. Quanto maior a diferença de potencial utilizada para acelerar os elétrons em direção ao alvo, maior será a probabilidade do elétron ser desacelerado no campo nuclear, propiciando a produção de mais fótons de raios $\mathrm{X}$ de energia média maior (figura $5 b)$. Esta diferença de voltagem é ajustada no controle de quilovoltagem $(\mathrm{kV})$ no painel do aparelho (BITELLI, 2006; THRALL, 2010; CURRY et al., 1990).

\subsubsection{Corrente do tubo ( $m A)$}

A intensidade de fótons é influenciada pelo número de elétrons que interagem no alvo. Quanto maior o número de elétrons disponíveis no processo de interação, maior o número de fótons de raios X gerados (figura 5a) (BITELLI, 2006; CURRY et al.1990). 
A unidadeo miliampere (mA) está diretamente ligado ao tempo (s) que é determinado no painel do aparelho, portanto geralmente utiliza-se o conceito de rendimento do tubo (mAs) que é usado para quantificar a quantidade de radiação produzida pela ampola de raios $\mathrm{X}$, a tabela 2 apresenta alguns exemplos das possíveis combinações (THRALL, 2010).

Tabela 2 - Rendimento do tubo constantes que podem ser produzidas por diversas combinações de miliampere e tempo.

\begin{tabular}{ccc}
\hline $\mathbf{m A}$ & Tempo (s) & mAs \\
\hline 50 & 0,1 & 5 \\
100 & 0,05 & 5 \\
500 & 0,01 & 5 \\
1.000 & 0,005 & 5 \\
\hline
\end{tabular}

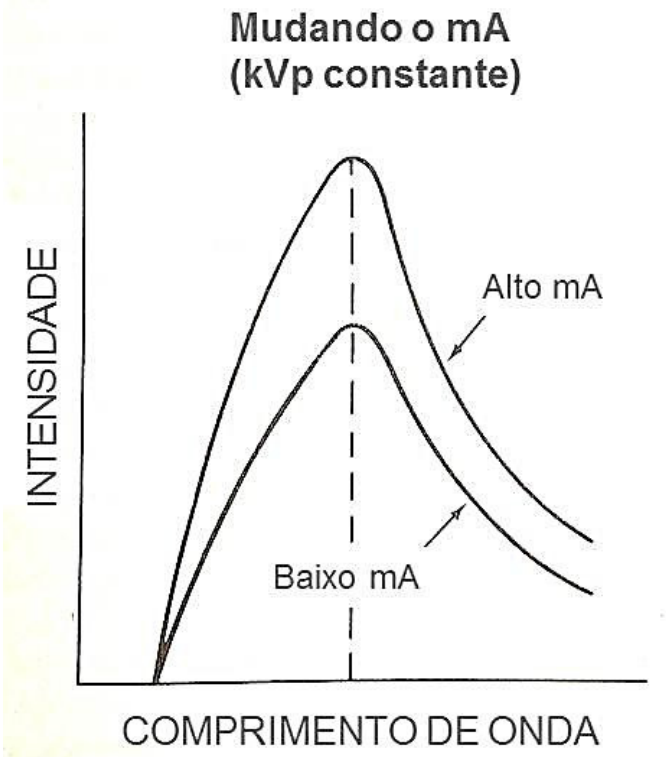

(a)

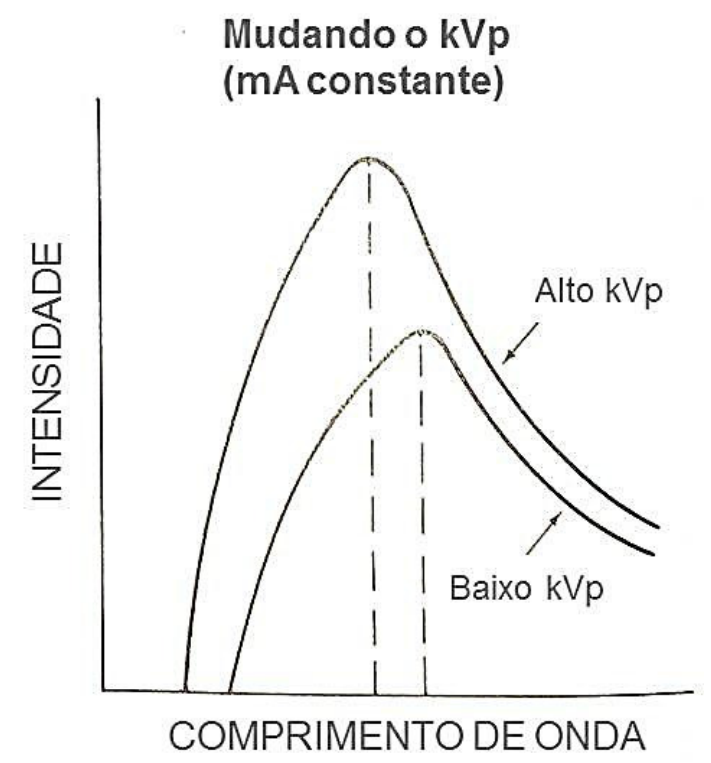

(b)

Figura 5 - $O$ efeito da mudança de $\mathrm{mA}$ na qualidade e intensidade do feixe de raios $\mathrm{X}$ (a). $\mathrm{O}$ efeito da mudança do $\mathrm{kVp}$ na qualidade e intensidade do feixe de raios $\mathrm{X}$ (b). 


\subsubsection{Filtração}

Os filtros modificam o espectro da radiação quando adicionados na saída do feixe de raios $\mathrm{X}$ e, portanto modificam também a intensidade da radiação (figura 6). Os filtros são utilizados em equipamentos convencionais para absorver os fótons de menor energia presentes no feixe e de minimizar a quantidade de fótons absorvidos na superfície da pele, além de impedir que a radiação característica do material aumente a dose na pele do paciente (BITELLI, 2006; CURRY et al., 1990).

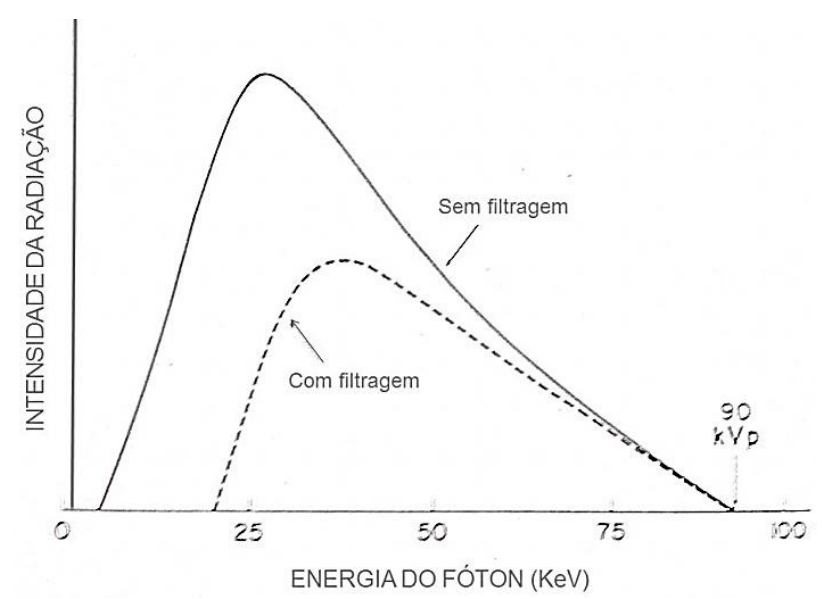

Figura 6 - Diferença de qualidade e intensidade do feixe de raios X sem filtragem e com filtragem.

\subsubsection{Material do alvo}

Quanto maior o número atômico do elemento utilizado como alvo, maior será a probabilidade do elétron perder energia cinética no processo de interação por radiação de freamento, proporcionando mais intensidade de fótons de raios $\mathrm{X}$ devido ao maior número de fótons produzido, os materiais mais utilizados são tungstênio ( $Z=74)$ e molibdênio ( $Z=40)$ (BITELLI, 2006; CURRY et al., 1990).

\subsection{Interação da radiação com a matéria}

Sob o ponto de vista físico, as radiações ao interagir com um material, podem nele provocar excitação atômica ou molecular, ionização ou ativação do núcleo (TAUHATA, 2003) (CURRY et al.,1990) (OKUNO \& YOSHIMURA, 2010). 


\subsubsection{Excitação atômica ou molecular}

Interação onde elétrons são deslocados de seus orbitais de equilíbrio e, ao retornarem, emitem energia excedente sob a forma de luz ou raios $\mathrm{X}$ característicos. A figura 7 ilustra esse tipo de interação (TAUHATA, 2003) (CURRY et al.,1990).

\subsubsection{Ionização}

Interação onde elétrons são removidos dos orbitais pelas radiações, resultando elétrons livres de alta energia, íons positivos ou radicais livres quando ocorrem quebra de ligações químicas. A figura 7 ilustra esse tipo de interação (TAUHATA, 2003).

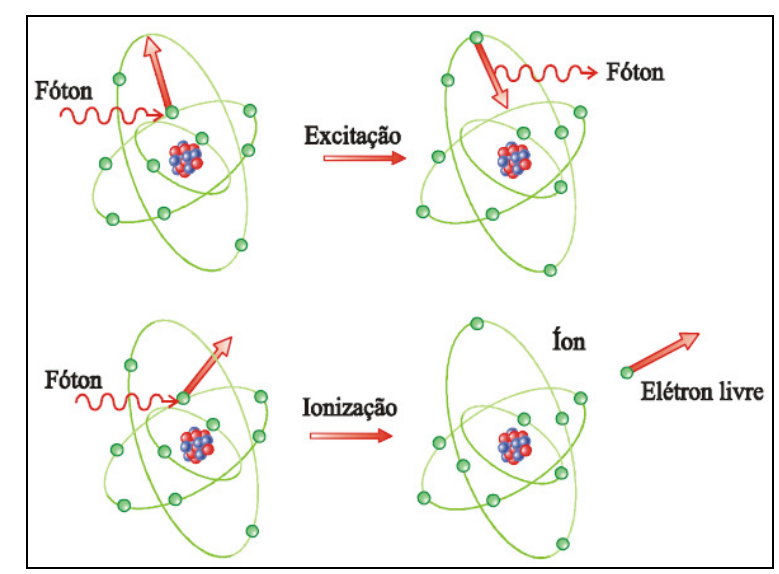

Figura 7 - Modo de interação da radiação com a matéria (TAUHATA, 2003).

\subsubsection{Radiações diretamente e indiretamente ionizantes}

No processo de transferência de energia de uma radiação incidente para a matéria, as radiações que têm carga, como elétrons, partículas alfa e fragmentos de fissão, atuam principalmente por meio de seu campo elétrico e transferem sua energia para muitos átomos ao mesmo tempo, e são denominadas radiações diretamente ionizantes. As radiações que não possuem carga, como as radiações eletromagnéticas e os nêutrons, são chamadas de radiações indiretamente ionizantes, pois interagem individualmente transferindo sua energia para elétrons, que irão provocar novas ionizações (SPRAWLS, 1993)

Quando um feixe de raios $\mathrm{X}$ ou gama atravessa um objeto, podem ocorrer principalmente os seguintes tipos de interações:

a) Ele pode penetrar na matéria sem interagir com a mesma, 
b) Ele pode interagir com a matéria e ser completamente absorvido, transferindo toda sua energia para o meio,

c) Ele pode interagir com a matéria e ser espalhado ou defletido de sua direção original, perdendo parte de sua energia (SPRAWLS, 1993).

Os principais efeitos que podem ocorrer quando a radiação eletromagnética interage com elétrons ou com o núcleo atômico são: espalhamento coerente, efeito Compton, efeito fotoelétrico, produção de pares e fotodesintegração. A seguir, são descritas brevemente esses tipos de interações (SPRAWLS, 1993).

\subsubsection{Espalhamento coerente}

No espalhamento coerente, o fóton causa uma excitação no átomo. Espontaneamente, o átomo volta ao estado fundamental, emitindo um fóton de mesma energia do fóton incidente. É importante notar que, nesse tipo de interação não há transferência de energia ao átomo. Se a interação ocorre com o núcleo, o processo recebe o nome de espalhamento Thomson. Quando o fóton interage com um elétron orbital, o processo é denominado espalhamento Rayleigh. A probabilidade de ocorrência do espalhamento coerente está diretamente relacionada com o quadrado do número atômico do material alvo e inversamente proporcional à energia do fóton. Além disso, sua ocorrência está limitada a fótons de energias inferiores a $10 \mathrm{keV}$, que está aproximadamente no intervalo das energias de ligação dos átomos (SPRAWLS, 1993; CURRY et al.,1990).

Nesse processo, o fóton incidente interage com o átomo, causando uma excitação no mesmo. Espontaneamente, o átomo emite um fóton com energia igual à do fóton incidente (SPRAWLS, 1993).

\subsubsection{Efeito fotoelétrico}

O efeito fotoelétrico é caracterizado pela transferência total da energia da radiação $\mathrm{X}$ ou gama a um único elétron orbital, que é expelido com uma energia cinética $\left(\mathrm{E}_{\mathrm{c}}\right)$ bem definida, demostrada na equação 2 (TAUHATA, 2003). 


$$
E_{c}=h v-B_{E}
$$

Em que:

$\mathrm{E}_{\mathrm{C}}$ é a energia cinética do fóton,

h é a constante de Planck,

$\nu$ é a frequência da radiação,

$\mathrm{B}_{\mathrm{E}}$ é a energia de ligação do elétron orbital.

Por meio da figura 8, pode-se observar a ocorrência do efeito fotoelétrico. Esse ocorre quando um fóton incidente é totalmente absorvido, causando a ionização de uma molécula. O resultado da ionização é a ejeção de um fotoelétron e o "desaparecimento" do fóton incidente. A lacuna deixada pelo elétron ejetado é preenchida por elétrons de camadas mais energéticas, e o excesso de energia é liberado na forma de radiação X, denominada radiação característica, uma vez que é característica da energia de ligação de cada camada que, por sua vez, varia de átomo para átomo. O átomo em questão torna-se um íon positivo devido à deficiência de elétrons (SPRAWLS, 1993).

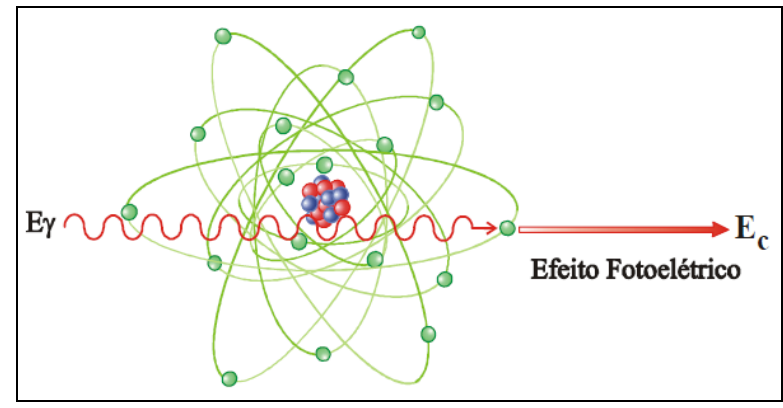

Figura 8 - Representação do efeito fotoelétrico (TAUHATA, 2003).

O efeito fotoelétrico é predominante para baixas energias e para elementos químicos de elevado número atômico $(\mathrm{Z})$. A probabilidade de ocorrência aumenta com $(Z)^{4}$ e decresce rapidamente com o aumento da energia.

\subsubsection{Efeito Compton}

No efeito Compton, o fóton é espalhado por um elétron de baixa energia de ligação, que recebe somente parte de sua energia, continuando sua sobrevivência dentro do material 
em outra direção. Como a transferência de energia depende da direção do elétron emergente e esta é aleatória, de um fóton de energia fixa podem resultar elétrons com energia variável, com valores de zero até um valor máximo. O efeito Compton está representado na figura 9 (CURRY et al., 1990; TAUHATA, 2003).

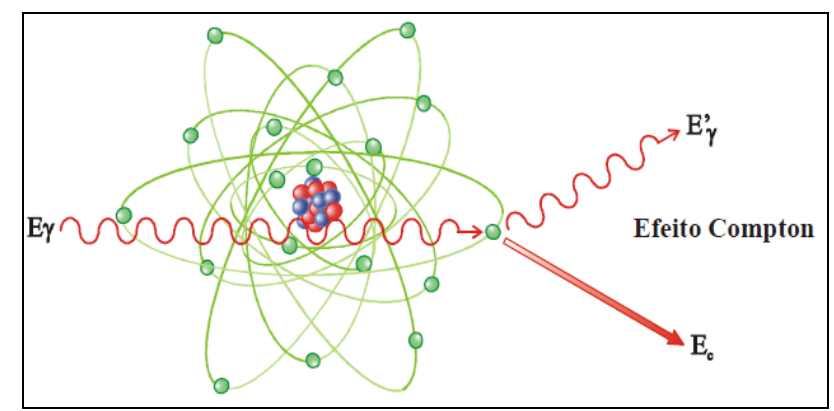

Figura 9 - Representação do efeito Compton (TAUHATA, 2003).

O efeito Compton é um processo de colisão entre um fóton incidente e elétrons livres, onde na categoria de elétrons livres se enquadra aqueles em que a energia de ligação com o núcleo é pequena o suficiente, quando comparada à energia do fóton incidente. $\mathrm{O}$ efeito Compton acontece quando somente uma parcela da energia do fóton incidente é absorvida pelo átomo e um fóton de menor energia é produzido. Como esse fóton deixa o átomo com uma direção diferente do fóton incidente, o efeito Compton é também designado como espalhamento incoerente ou inelástico. A energia absorvida pelo átomo é suficiente para arrancar um elétron, deixando o átomo ionizado (SPRAWLS, 1993).

A energia do fóton espalhado é igual à diferença entre a energia do fóton incidente e a soma da energia de ligação do elétron e da energia cinética do elétron ejetado. Matematicamente, a energia transferida pode ser representada de acordo com a equação 3:

$$
h v=h v^{\prime}+E_{C}
$$

Em que:

$h v$ é a energia do fóton incidente;

$h v^{\prime}$ é a energia do fóton emitido;

$\mathrm{E}_{\mathrm{C}}$ é a energia cinética do elétron ejetado. 
Quando a energia de ligação dos elétrons orbitais se torna desprezível face à energia do fóton incidente, a probabilidade de ocorrência de espalhamento Compton aumenta consideravelmente. A probabilidade de ocorrência do efeito Compton não depende do número atômico do material alvo, uma vez que a interação ocorre com elétrons livres. Por isso, sua ocorrência está diretamente ligada à densidade eletrônica do material, e inversamente relacionada à energia do fóton incidente (TAUHATA, 2003; SPRAWLS, 1993).

\subsubsection{Produção de Pares}

Uma das formas predominantes de absorção da radiação eletromagnética de alta energia é a produção de par elétron-pósitron. Este efeito ocorre quando fótons de energia superior a 1,022 MeV passam perto de núcleos de número atômico elevado, interagindo com o forte campo elétrico nuclear. Nesta interação, ilustrada na figura 10, a radiação desaparece e dá origem a um par elétron-pósitron. As duas partículas transferem a sua energia cinética para o meio material, sendo que o pósitron volta a se combinar com um elétron do meio e dá origem a dois fótons, cada um com energia de $511 \mathrm{keV}$ (SPRAWLS, 1993).

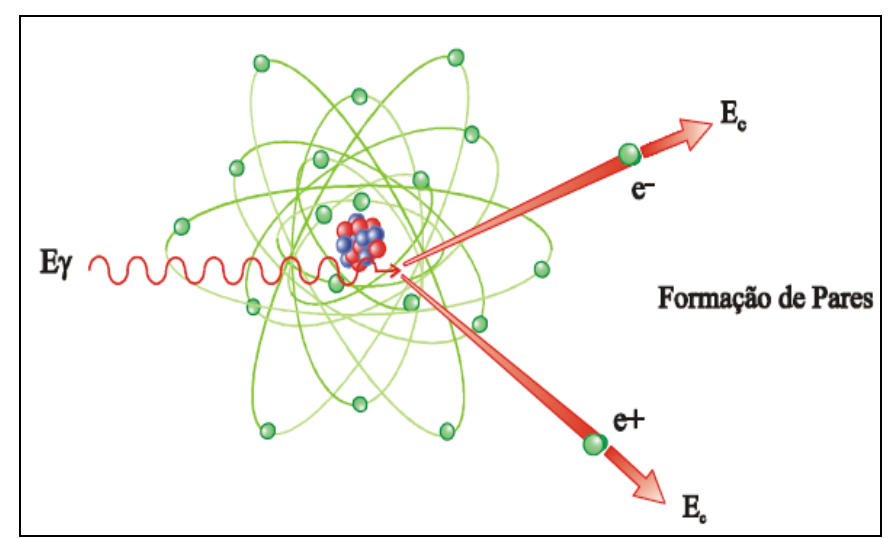

Figura 10 - Representação da interação produção de pares (TAUHATA, 2003). 


\subsection{Grandezas Radiológicas}

3.5.1. Exposição $(X)$

É uma medida baseada no número de pares iônicos produzidos no ar pela radiação incidente e é expressa, no SI, como Coulombs por quilograma, a equação 4 mostra essa relação (THRALL, 2010).

$$
X=\frac{d Q}{d m}=\frac{[C]}{\left[K_{g}\right]}
$$

Em que:

$\mathrm{d} Q$ é a quantidade total de cargas de um único sinal (positivas ou negativas) produzidas no ar, quando todos os elétrons liberados pelos fótons em um elemento de volume de ar, cuja massa é dm, são completamente freados no ar (TAUHATA, 2003; SPRAWLS, 1993).

Anteriormente a unidade convencional para exposição era o roentgen $(\mathrm{R})$, mas no sistema internacional (SI) a unidade é fornecida por coulomb por kilograma no ar $(\mathrm{C} / \mathrm{Kg})$. Um Roentgen é igual a $2,58 \times 10^{-4} \mathrm{C} / \mathrm{Kg}$ (THRALL, 2010)

\subsubsection{KERMA}

O kerma (Kinetic Energy Released per unit of mass) está definido e é representado pela equação 5:

$$
K=\frac{d E_{t r}}{d m}=\frac{U]}{[K g]}
$$

Em que:

$\mathrm{dE}_{\mathrm{tr}}$ é a soma de todas as energias cinéticas iniciais de todas as partículas carregadas liberadas por partículas neutras ou fótons, incidentes em um material de massa dm (IAEA, 2007). 


\subsubsection{Kerma incidente no ar}

O kerma incidente no ar $\left(K_{i}\right)$ é a medida no centro do feixe de raios $\mathrm{X}$ na superfície do paciente ou simulador, desconsiderando o retro-espalhamento da radiação (IAEA, 2007).

\subsubsection{Kerma de entrada na superfície}

O kerma de entrada na superfície $\left(K_{e}\right)$ é medido no centro do feixe de raios $\mathrm{X}$ na superfície do paciente ou simulador, considerando o retro-espalhamento da radiação, equação 6:

$$
K_{e}=K_{i} \cdot \mathrm{B}
$$

Em que:

$K_{\mathrm{i}}$ é kerma incidente no ar,

B é fator de retro-espalhamento.

A medida de kerma de entrada na superfície, $K_{e}$, fornece uma avaliação direta da dose do paciente (IAEA, 2007).

\subsubsection{Dose Absorvida}

Por definição dose absorvida é a grandeza dosimétrica fundamental expressa pela equação 7:

$$
\mathrm{D}=\mathrm{dE} / \mathrm{dm}
$$

Em que:

dE é a energia média depositada pela radiação em um volume elementar de matéria de massa dm.

A unidade no sistema internacional é o joule por quilograma $(\mathrm{J} / \mathrm{kg})$, denominada gray (Gy) (CNEN, 2011).

Conforme está definido, o termo dose absorvida se aplica a qualquer tipo de radiação e a qualquer material. A unidade antiga era medida em rad (radiation absorved dose), sendo que 1 rad equivale a 100 ergs de energia absorvida por $1 \mathrm{~g}$ de matéria. Nas 
unidades do SI, a grandeza dose absorvida é expressa em $\mathrm{J} / \mathrm{kg}$ ou Gray (Gy) sendo que $1 \mathrm{rad}=100 \mathrm{ergs} / \mathrm{g}=0,01 \mathrm{~J} / \mathrm{kg}=0,01 \mathrm{~Gy}$ (SPRAWLS, 1993; TAUHATA, 2003).

\subsubsection{Dose Equivalente}

Por definição Dose equivalente é expressa conforme a equação 9:

$$
\mathrm{H}_{\mathrm{T}}=\mathrm{D} \cdot \mathrm{W}_{\mathrm{R}}
$$

Em que:

D é dose absorvida,

$\mathrm{W}_{\mathrm{R}}$ é o fator de ponderação da radiação.

A unidade no sistema internacional é o joule por quilograma $(\mathrm{J} / \mathrm{kg})$, denominada sievert (Sv) (CNEN, 2011; IAEA, 2007). A tabela 3 ilustra os fatores de qualidade para alguns tipos de radiação:

Tabela 3 - Fatores de qualidade Q para os diferentes tipos de radiação.

\begin{tabular}{lc}
\hline Tipo de radiação & $\boldsymbol{W}_{\boldsymbol{R}}$ \\
\hline Raios-X, raios- $\gamma$, elétrons, pósitrons e múons & 1 \\
Nêutrons $<10 \mathrm{keV}$ & 5 \\
$10 \mathrm{keV}-100 \mathrm{keV}$ & 10 \\
$100 \mathrm{keV}-2 \mathrm{MeV}$ & 20 \\
$2 \mathrm{MeV}-20 \mathrm{MeV}$ & 10 \\
$<20 \mathrm{MeV}$ & 5 \\
Prótons $>2 \mathrm{MeV}$ & \\
\hline Partículas- $\alpha$, fragmentos de fissão de núcleos pesados não-relativísticos & 2 \\
\hline
\end{tabular}




\subsubsection{Dose Efetiva $\left(H_{e}\right)$}

Por definição Dose Efetiva (E) é a soma das doses equivalentes ponderadas nos diversos órgãos e tecidos, conforme a equação 10.

$$
E=\Sigma_{T} W_{T} \cdot H_{T}
$$

Em que:

$\mathrm{H}_{\mathrm{T}}$ é a dose equivalente no tecido ou órgão,

$\mathrm{W}_{\mathrm{T}}$ é o fator de ponderação de órgão ou tecido.

A unidade no sistema internacional é o joule por quilograma $(\mathrm{J} / \mathrm{kg})$, denominada sievert (Sv) (CNEN, 2011; IAEA, 2007).

Essa é uma grandeza utilizada para se avaliar o dano de um determinado tipo de radiação em diferentes tecidos biológicos. Está baseada no princípio de que, para certo nível de proteção, os riscos devem ser os mesmos se o corpo for irradiado uniformemente, ou se a radiação é localizada em determinado órgão. Para isso, a cada órgão se relaciona uma constante de ponderação, alguns dos quais estão representados na tabela 4 (TAUHATA, 2003):

Tabela 4 - Fatores de ponderação para alguns órgãos do organismo humano.

\begin{tabular}{cc}
\hline Órgão & Fator de ponderação $\left(W_{T}\right)$ \\
\hline Gônadas & 0,25 \\
Mama & 0,15 \\
Medula óssea & 0,12 \\
Pulmão & 0,12 \\
Tireóide & 0,03 \\
Osso & 0,03 \\
Restante do corpo & 0,06 \\
\hline
\end{tabular}




\subsection{História da Dosimetria Termoluminescente}

Por definição, a radiação ionizante absorvida pela matéria produz ionizações. Parte dessa energia absorvida é transformada em calor, enquanto uma pequena fração é utilizada para quebrar ligações químicas. Em alguns tipos de materiais, a energia pode ser armazenada em estados metaestáveis. O fenômeno da liberação de fótons visíveis por aquecimento térmico é denominado termoluminescência. Esse fenômeno tem sido observado por séculos, sempre que certos fluoretos e pedras calcárias eram aquecidos (CAMERON et al. 1968; SAW, 2002).

Daniels, em 1950, propôs que a termoluminescência poderia ser utilizada como instrumento para medida de radiação (dosímetro). Ele e seu grupo desenvolveram a instrumentação para essa proposta. Em meados dos anos 50, Daniels e seus ajudantes aplicaram a termoluminescência pela primeira vez. Os dosímetros compostos por fluoreto de lítio ( $\mathrm{LiF}$ ) foram utilizados para quantificar a radiação após um teste com uma bomba. A dosimetria termoluminescente (TL) também foi utilizada por Daniels e Brucer para a dosimetria in vivo. O paciente recebeu uma dose terapêutica de iodo radioativo $\left({ }^{131} \mathrm{I}\right)$ e, logo após, tragou um cristal de LiF. O mesmo foi recuperado após atravessar o trato digestivo, e a termoluminescência foi medida para determinar a radiação recebida pelo paciente (CAMERON et al., 1968; SAW, 2002).

Embora a termoluminescência provocada por raios $\mathrm{X}$ ou gama tenha sido observada previamente a sua aplicação para dosimetria de radiação não foi sugerida. Alguns alunos de Daniels pesquisaram a termoluminescência, mas os aspectos da dosimetria TL do trabalho de Daniels foram interrompidos por volta de 1955. Em 1960, as pesquisas com dosimetria TL na Universidade de Wisconsin foram retomadas por J.R. Cameron, em colaboração com Daniels e com N. M. Johnson, um estudante graduado em geologia (CAMERON et al., 1968).

No final dos anos 50 diversos outros grupos iniciaram trabalhos com dosimetria TL. O grupo de Schulman no Laboratório de Pesquisas Navais desenvolveu um dosímetro composto por fluoreto de cálcio dopado com manganês $\left(\mathrm{CaF}_{2}: \mathrm{Mn}\right)$. $\mathrm{O}$ grupo MBLE na Bélgica desenvolveu um tipo de dosímetro-militar de fluoreto de cálcio $\left(\mathrm{CaF}_{2}\right)$. Outros trabalhos foram executados na Bélgica, na União Soviética e na Alemanha (CAMERON et al., 1968; SAW, 2002). 


\subsection{Dosímetros Termoluminescentes (DTL)}

O fenômeno da radiotermoluminescência é aproveitado principalmente nos dosímetros de leitura indireta (que necessitam de outros equipamentos para cálculo de dose). Os materiais termoluminescentes são portadores de um estado de excitação quando submetidos à radiação e, após irradiação quando aquecidos emitem luz, proporcional a dose de radiação recebida (BITELLI, 2006).

\subsubsection{Propriedades dos DTL}

Um material TL para uso dosimétrico deve combinar diversas propriedades, tais como (OBERHOFER \& SCHARMANN, 1979; BITELLI, 2006):

- $\quad$ Alta concentração de armadilhas de elétrons (ou buracos) e uma alta eficiência na emissão de luz associada ao processo de recombinação;

- Estabilidade de armazenamento suficiente das armadilhas de elétrons (ou buracos) de modo a não causar um decaimento indesejável durante o período de armazenamento a temperatura ambiente ou a certas variações de temperatura;

- Resistência contra fatores ambientais: luz, umidade, solvente orgânico ou gases;

- Sensibilidade de alguns mGy até alguns Gy;

- Possibilidade de reutilização;

- Precisão para o mesmo lote de aparelhos;

- Reprodutibilidade e Repetibilidade;

- Boa linearidade;

- Fácil aquisição do dosímetro aliado ao baixo custo.

\subsection{2. $L i F: M g, T i$}

O LiF:Mg,Ti foi um dos principais materiais comercializados pela indústria TL há mais de três décadas atrás, e o material TL mais amplamente utilizado na área de dosimetria pessoal. Sua popularidade foi devido a algumas características, tais como: razão equivalência-tecido bem próximo, confiabilidade nas medidas e alta sensibilidade (McKEEVER et al.,1995). 
A equivalência do LiF:Mg,Ti ao tecido é bastante apropriada e a dependência de sua resposta com a energia, taxa de dose e temperaturas de utilização e armazenamento são pequenas no intervalo de doses em radiodiagnóstico.

\subsection{3. $\mathrm{CaSO}_{4}: \mathrm{Dy}$}

$\mathrm{O} \mathrm{CaSO}_{4}$ :Dy é um tipo de DTL desenvolvido e produzido pelo Laboratório de Matérias Dosimétricos (LMD-IPEN), comercializado na forma de pó e pastilhas de $6 \mathrm{~mm}$ de diâmetro com 0,2 e 0,8 mm de espessura, com massa de 10 a $50 \mathrm{mg}$, respectivamente. Ele é utilizado na monitoração das radiações de fótons e beta e vem sendo amplamente utilizado em medidas de doses na área médica.

O número atômico efetivo do $\mathrm{CaSO}_{4}: \mathrm{Dy}\left(\mathrm{Z}_{\mathrm{ef}}=15,3\right)$ é aproximadamente 2 vezes superior ao do tecido humano, conforme se considere este 7,0 ou 7,5, isso pode ser um problema, pois materiais com maior número atômico efetivo (Zef) apresentam o efeito fotoelétrico, tornando-se mais pronunciados para energias de fótons abaixo de $100 \mathrm{keV}$, ou seja, o $\mathrm{CaSO}_{4}$ :Dy sofre grande dependência energética mas a interposição de filtros permite correções da dependência energética porque:

1- As radiações de baixa energia são mais intensamente atenuadas por estes filtros do que as maiores.

2- Embora gerem maior sinal TL, devido a 1; os feixes de fótons de energia baixa atingem o material com intensidade menor.

Assim, os efeitos 1 e 2 diminuem a dependência energética. Utilizar estes efeitos para corrigir a dependência energética, ainda que pareça simples, na prática é um problema difícil de engenharia de materiais. Há que se avaliar não só o tipo de material (coeficiente de atenuação), como também sua espessura ou geometria para tornar o DTL prático (CAMPOS, 2005).

\subsubsection{Funcionamento de um DTL}

Certos materiais quando aquecidos, após serem expostos à radiação ionizante, tornam-se capazes de emitir luz. Esses materiais são ditos termoluminescentes (TL). A termoluminescência é explicada através do modelo de bandas para os níveis de energia dos elétrons nos sólidos. Os materiais TL são, em geral, cristais iônicos, nos quais a banda 
de valência (BV) se encontra repleta de elétrons e a banda de condução (BC) vazia, ambas separadas por uma faixa larga de estados energéticos não permitidos aos elétrons, conhecida como banda proibida (BP) (McKEEVER, 1985).

De um modo geral, quando os elétrons de um sólido são excitados por absorção de radiação eletromagnética ou por outro processo qualquer, eles não permanecem por muito tempo nos respectivos níveis mais altos, decaindo por vários processos competitivos. Se o processo de decaimento mais provável envolve a emissão de radiação eletromagnética na região visível do espectro, dizemos que existe luminescência. A figura 11 esquematiza os processos de excitação e estimulação térmica em um cristal TL.

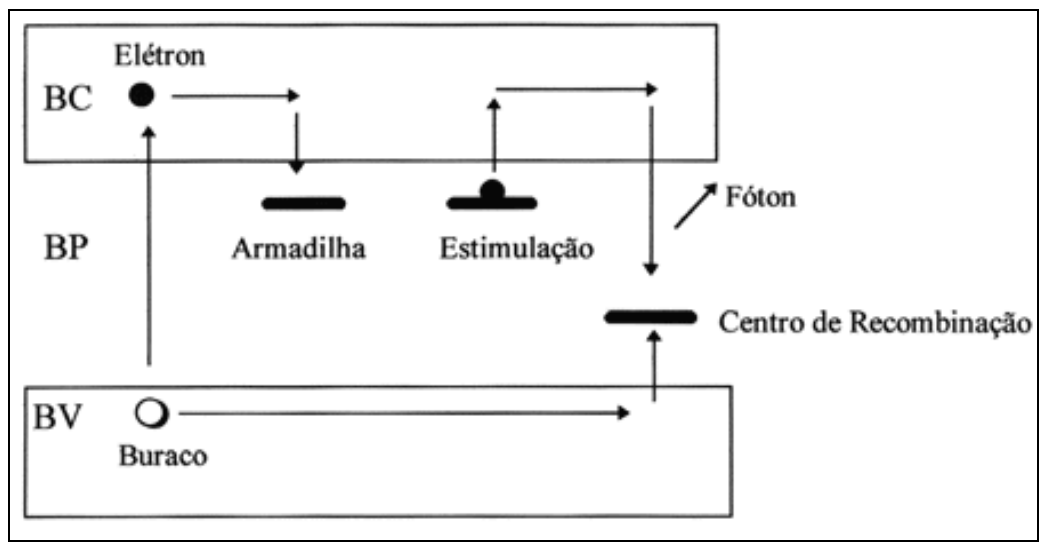

Figura 11 - Diagrama esquemático de excitação e estimulação térmica em um cristal TL (McKEEVER, 1985).

Nos sólidos, a luminescência está ligada às impurezas e aos defeitos da estrutura cristalina. Quando um elétron da banda de valência é transferido para a banda de condução, deixa naquela uma lacuna, ou seja, um nível incompleto. Se a estrutura cristalina do sólido em questão não contém defeitos nem impurezas, o elétron volta à banda de valência com a emissão de radiação eletromagnética com uma energia muito alta para ficar na região visível do espectro. Se a rede contiver algumas impurezas que originem níveis de energia entre as bandas de valência e de condução, um elétron de um nível de energia de impureza inferior pode preencher a lacuna na banda de valência, e um elétron da banda de condução pode preencher um dos níveis de energia de impureza superiores, com a emissão, nos dois casos, de radiação eletromagnética com energia muito baixa para ficar na região visível do espectro. Um elétron pode passar de um nível de energia de impureza superior para um nível de energia de impureza inferior que esteja 
vazio, com a emissão de radiação eletromagnética com energia que a situe na região visível do espectro, e isso é o que constitui a luminescência (McKEEVER, 1985).

Em certos casos, o elétron da banda de condução pode passar para um nível de energia chamado armadilha, do qual ele não pode passar ao nível de energia de impureza mais baixo, por uma transição radioativa, sem violar um ou outro princípio de conservação. O elétron se encontra, então, num estado metaestável, e permanece nesse estado por um tempo que pode ser de muitos segundos (muito grande para a escala atômica), até que algum processo o faça regressar à banda de condução, passando por todas as etapas descritas acima.

A quantidade de luz é mensurável, aumentando a sua intensidade com a população de elétrons armadilhados, ou seja, essa última é dependente da exposição fornecida ao cristal (McKEEVER, 1985).

\subsubsection{Curva resposta TL em função da dose}

Os dosímetros TL apresentam inúmeras vantagens como já ressaltado no tópico anterior, entretanto existe um limite inferior de detecção (LID), abaixo do qual o DTL não diferencia as doses com as quais é irradiado; daí até certo ponto da curva, a resposta é linear com a dose, com o aumento da dose as propriedades dos DTL podem sofrer alterações e, tanto surge a região supralinear, a partir de onde a resposta TL satura e a sensibilidade do dosímetro é reduzida pelos danos provocados pela irradiação (OBERHOFER \& SCHARMANN, 1979).

A curva resposta TL em função da dose ideal de um DTL é linear sobre todo o intervalo de exposição útil, de modo a simplificar a calibração e o seu uso. Alguns DTLs não respondem linearmente e necessitam de uma calibração adequada para o intervalo de dose de interesse. Geralmente, a parte linear é gradual, então, a resposta pode ser aproximada como linear sobre o intervalo limitado (CAMERON et al.,1968).

Em alguns materiais a resposta TL aumenta, de início, linearmente com a dose absorvida de radiação, observando-se posteriormente um crescimento mais rápido do que o linear. A este último comportamento dá-se o nome de supralinearidade, que é representado na figura 12 (CAMPOS, 1998). 


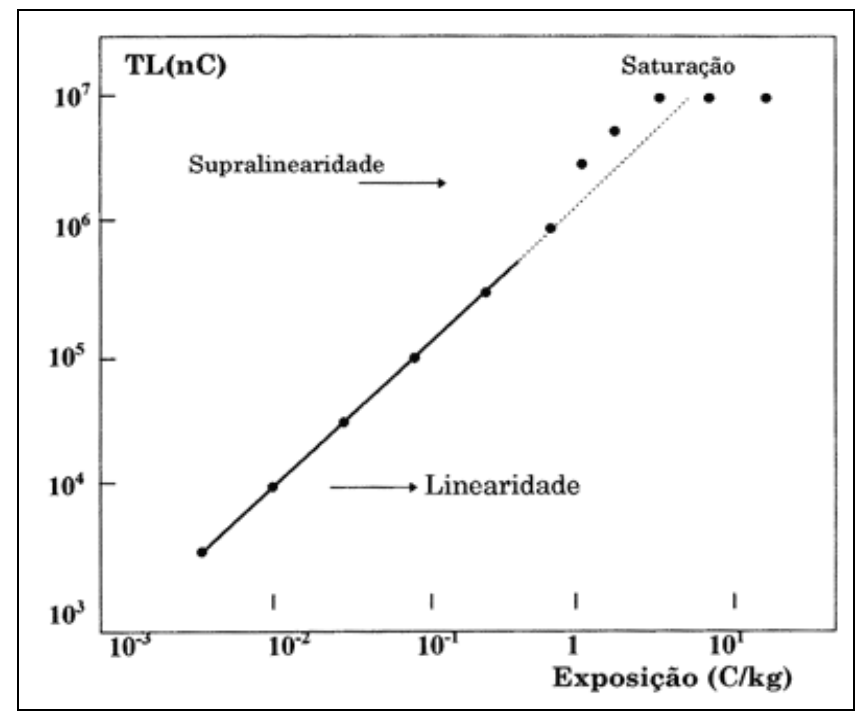

Figura 12 - Curva resposta TL em função da exposição, mostrando a região de supralinearidade (CAMPOS L. L., 1998).

\subsubsection{Tratamento térmico}

O tratamento térmico tem por finalidade devolver ao dosímetro as condições existentes antes da sua primeira exposição à radiação ionizante, ou seja, consiste em remover os sinais residuais referentes a exposições anteriores, tornando-o apto para reutilização, sem perda das suas propriedades dosimétricas (CAMERON et al., 1968; CAMPOS, 1998). O processo de aquecimento também ajusta outro fator crítico, que é a sensibilidade do dosímetro. Por isso, grupos de dosímetros devem ser submetidos a aquecimentos idênticos.

\subsection{Dosimetria na Radiologia Veterinária}

A norma da NCRP Report $\mathrm{n}^{\circ} 148$ proporciona um guia para o desenvolvimento de um programa efetivo de segurança radiológica e recomendações para a utilização de equipamentos radiográficos, fluoroscópicos e terapêuticos em medicina veterinária. Estas recomendações são designadas para alcançar os seguintes objetivos de radioproteção: prevenir a ocorrência de danos significativos causados pela radiação e limitar o risco de efeitos estocásticos, tais como câncer e efeitos genéticos. A exposição à radiação aos indivíduos deve ser controlada e limitada ajustando-se os seguintes parâmetros: aumento da distância do indivíduo até a fonte; redução do tempo de exposição e utilização de barreiras protetoras (blindagem) entre o indivíduo e a fonte (NCRP, 2004). 
Todos os trabalhadores devem receber monitoração individual e treinamento relativo à segurança em medidas radioprotetoras. Devem também ser conscientizados dos riscos relacionados a esta prática. Os riscos para os indivíduos expostos à radiação dentro destes limites recomendados é considerado muito pequeno; entretanto, o risco aumenta proporcionalmente de acordo com a dose de radiação recebida. Por este motivo, a NCRP recomenda a aplicação do princípio ALARA (“as low as reasonably achievable”) para todas as exposições (NCRP Report 148, 2004).

Embora as normas e medidas de radioproteção sejam designadas somente para os seres humanos, os fundamentos e elementos de proteção radiológica contidos nas normas da NCRP são também aplicáveis às práticas de radiologia e oncologia na área de medicina veterinária.

A dosimetria em animais ainda é pouco explorada no Brasil, e no exterior existem poucos trabalhos relacionado a área de dosimetria animal. A medida de dose em animais domésticos foram avaliadas na ordem de alguns mGy para exames específicos de tórax (VENEZIANI, 2010), não foram encontrados outros trabalhos relacionados a medida de dose no paciente animal.

A outra tendência é o estudo da proteção radiológica dos trabalhadores, auxiliares e indivíduos do público (proprietários). Estudos na Alemanha não apresentaram dose expressiva para trabalhadores dessa área (SEIFERT et al., 2007; SEIFERT et al., 2008). Trabalhos no hospital veterinário de UNAM no México demostraram que na sala de exame radiodiagnóstico, usando dosímetros distribuidos em pontos da sala de procedimento, existem inúmeros lugares onde a dose está dentro do BG. Entretanto os trabalhadores e estagiários tem usado doses acima do limite permissível (HERNÁNDEZ-RUIZ et al., 2012).

Embora o mercado de animais domésticos esteja em ampla ascensão econômica, tendo faturamentos bilionários nos últimos anos (VEJA, 2009), a área de pesquisa no que se diz respeito a dosimetria destes animais ainda é muito pobre. Por isso, esse trabalho teve como objetivo a avaliação do kerma de entrada na superfície da pele em animais (cães) submetidos a exames radiográficos, além de avaliar a dose espalhada no ambiente, corpo clínico e auxiliares. 


\subsection{Incerteza nas medidas}

As incertezas associadas às medidas podem ser classificadas como incertezas do tipo A e incertezas do tipo B. As incertezas do tipo A são determinadas ou estimadas por análises estatísticas, enquanto que as incertezas do tipo B são determinadas ou estimadas por outros métodos (não-estatísticos), ou seja, por julgamentos científicos de incertezas não-estatísticas. Elas incluem influências nos processos de medidas, aplicação dos fatores de correção ou de dados físicos obtidos da literatura (IAEA, 2005).

Portanto, as incertezas do tipo A são incertezas devido à dispersão do valor dos resultados obtidos em torno do valor verdadeiro, ou seja, de caráter aleatório, como o desvio padrão da média. As incertezas do tipo B são incertezas devido ao conjunto de medições que apresenta valores igualmente espaçados do valor verdadeiro, originados de erros instrumentais, ambientais e observacionais. A incerteza total das medidas é dada pela equação 6 (VUOLO, 1992).

$$
\sigma_{\text {Total }}^{2}=\sigma_{\text {estatistico }}^{2}+\sigma_{\text {sistemático }}^{2}
$$

Em que:

$\sigma_{\text {Total }}:$ Incerteza total;

$\sigma_{\text {estatistico }}:$ Incerteza associada ao erro estatístico;

$\sigma_{\text {sistemático }}$ : Incerteza associada ao erro sistemático. 


\section{MATERIAIS E MÉTODOS}

\subsection{Materiais}

Para a realização dessa pesquisa foram utilizados os seguintes materiais:

- 60 dosímetros termoluminescentes de sulfato de cálcio dopado com disprósio $\left(\mathrm{CaSO}_{4}: \mathrm{Dy}\right)$ produzidos pelo Instituto de Pesquisas Energéticas e Nucleares (IPEN/CNEN-SP).

- 96 dosímetros termoluminescentes de fluoreto de lítio dopado com magnésio e titânio (LiF:Mg,Ti) produzidos pela Harshaw Chemical Company (EUA).

- 20 porta-dosímetros plásticos com capacidade para três dosímetros. Foram utilizados porta-dosímetros com filtros de chumbo, chumbo furado e sem filtro (somente plástico);

- 4 Pulseiras porta-dosímetros;

- Simulador cúbico de polimetilmetacrilato (PMMA) de dimensões $15 \times 15 \times 30 \mathrm{~cm}$;

- Simulador de Latex e polietileno.

- Trena de 1 metro;

- Pinça para manuseio dos dosímetros;

\subsection{Equipamentos}

Os equipamentos utilizados para a realização das leituras e tratamentos dos dosímetros estão apresentados na figura 13.

- Leitora termoluminescente da marca HARSHAW modelo 4500 (FIG 13-A);

- Leitora termoluminescente da marca HARSHAW modelo 5500 (FIG 13-B);

- 1 Forno tipo mufla marca VULCAN modelo 3-550 PD (FIG 13-C);

- 1 Estufa cirúrgica marca Fanem modelo 315-IEA 11200 (FIG 13-D); 


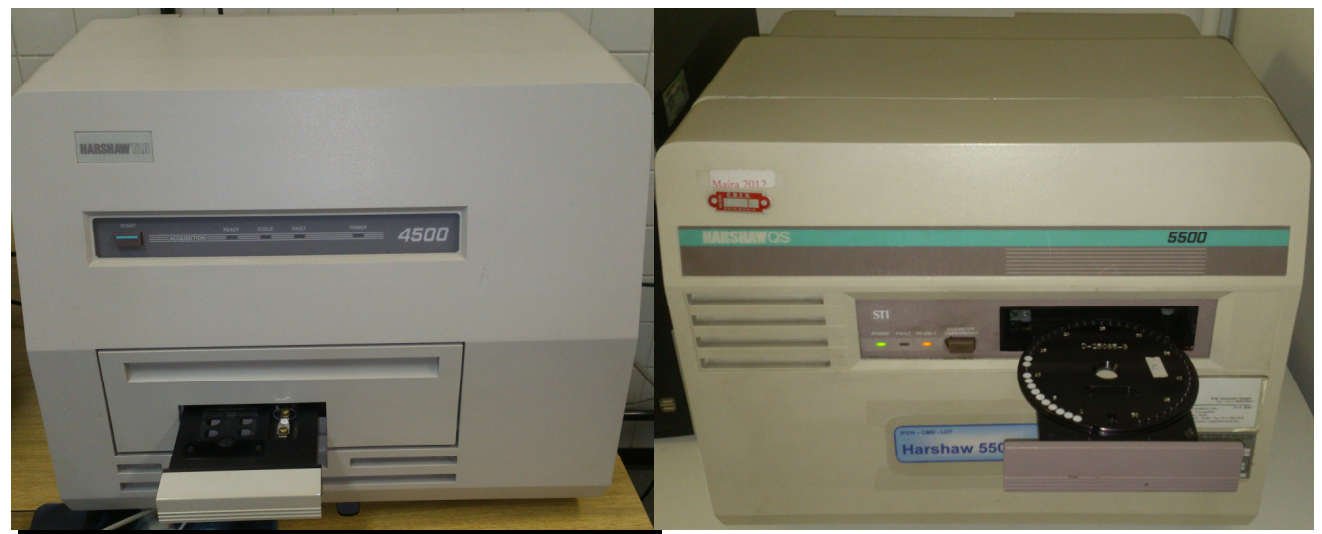

(A)

(B)

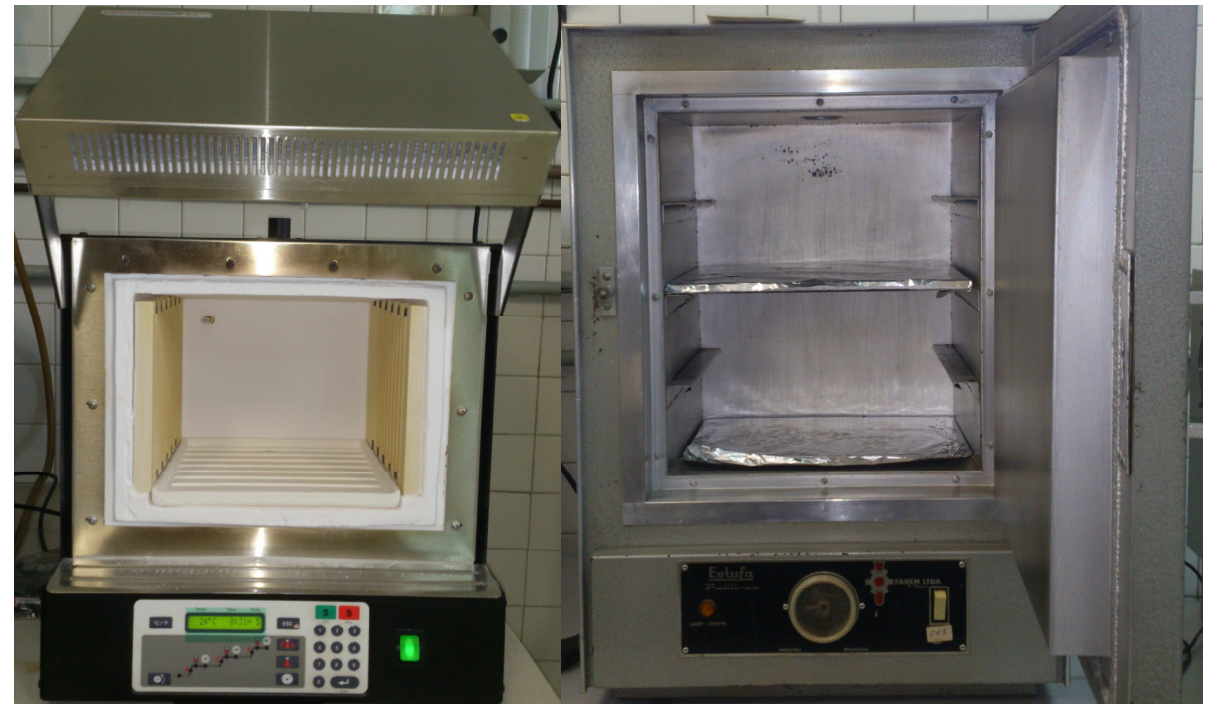

(C)

(D)

Figura 13 - Equipamento utilizados para leitura e tratamentos dos dosímetros TL; (A) Leitora Harshaw 4500; (B) Leitora Harshaw 5500; (C) Forno Vulcan; (D) Estufa cirúrgica Fanen

\subsection{Sistemas de irradiação}

Foram utilizados dois sistemas de irradiação: um para a construção da curva resposta TL em função da dose e outro para a irradiação dos dosímetros (reprodução das condições dos exames).

O primeiro sistema de irradiação é pertencente ao Laboratório de Calibração de Instrumentos (LCI-IPEN) e o segundo pertencente ao Centro Universitário de Rio Preto (UNIRP) (mesma máquina de raios $\mathrm{X}$ utilizada para a realização dos exames dos animais). Na tabela 5 são apresentados os parâmetros do sistema de irradiação pertencente ao LCIIPEN. 


\subsubsection{Sistemas de irradiação do Laboratório de Calibração de Instrumentos (LCI - IPEN)}

Para a realização da curva de resposta TL em função da dose foi adotado a qualidade da radiação RQR3, que no caso, é a que mais se aproxima das energias utilizadas no procedimento diagnóstico veterinário. Na tabela 5 são apresentados os parâmetros do sistema de irradiação pertencente ao LCI-IPEN.

Tabela 5 - Parâmetros de irradiação da máquina de raios X PANTAK/SEIFERT modelo ISOVOLT 160HS 5-160 kV/0.5-45.0 mA

\begin{tabular}{ccccccc}
\hline $\begin{array}{c}\text { Qualidade da } \\
\text { radiação }\end{array}$ & $\begin{array}{c}\text { Filtração } \\
\text { inerente } \\
(\mathbf{m m} \text { Al) }\end{array}$ & $\begin{array}{l}\text { Filtração } \\
\text { adicional } \\
(\mathbf{m m} \text { Al) }\end{array}$ & $\begin{array}{l}\mathbf{1}^{\mathbf{a}} \mathbf{C S R}^{(*)} \\
(\mathbf{m m} \mathbf{A l})\end{array}$ & $\begin{array}{l}\text { Tensão } \\
(\mathbf{k V})\end{array}$ & $\begin{array}{l}\text { Corrente } \\
(\mathbf{m A})\end{array}$ & $\begin{array}{l}\text { Energia } \\
\text { efetiva } \\
\text { (keV) }\end{array}$ \\
\hline RQR3 & 0,13 & 2,4 & 1,78 & 50 & 10 & 27,15 \\
\hline RQR5 & 0,13 & 2,8 & 2,58 & 70 & 10 & 30,15 \\
RQR7 & 0,13 & 2,5 & 3,97 & 90 & 10 & 33,05 \\
\hline
\end{tabular}

* CSR = Camada semi-redutora (HVL)

\subsubsection{Sistemas de irradiação do Setor de Radiologia Veterinária da UNIRP}

O equipamento utilizado no Setor de Radiologia Veterinária é inspecionado por empresas autorizadas e credenciadas pela ANVISA (Agência Nacional de Vigilância Sanitária), que realiza controles de qualidade anuais no equipamento a fim de averiguar se o mesmo encontra-se dentro das normas de controle de qualidade. Na tabela 6 são apresentados os parâmetros do sistema de irradiação do Departamento de radiologia da UNIRP.

Tabela 6 - Parâmetros de irradiação da máquina de raios-X Raicenter.

\begin{tabular}{cccccc}
\hline $\begin{array}{c}\text { Qualidade da } \\
\text { radiação }\end{array}$ & $\begin{array}{l}\text { Filtração } \\
\text { adicional } \\
(\mathbf{m m} \mathbf{A l})\end{array}$ & $\begin{array}{l}\mathbf{1}^{\mathbf{a}} \mathbf{C S R} \\
(\mathbf{m m} \mathbf{A l})\end{array}$ & $\begin{array}{l}\text { Tensão } \\
(\mathbf{k V})\end{array}$ & $\begin{array}{l}\text { Corrente } \\
(\mathbf{m A})\end{array}$ & $\begin{array}{l}\text { Energia } \\
\text { efetiva (keV) }\end{array}$ \\
\hline--- & ---- & 2,3 & 80 & 200 & 26,67 \\
\hline
\end{tabular}

* CSR = Camada semi-redutora (HVL) 


\subsection{Metodologia}

\subsubsection{Tratamento térmico dos dosímetros}

Para o tratamento térmico pré-irradiação os dosímetros de $\mathrm{CaSO}_{4}$ :Dy foram acomodados em uma bandeja de alumínio, com o auxílio de uma pinça anatômica, e levados ao forno a uma temperatura de $300^{\circ} \mathrm{C}$, durante o período de três horas.

O tratamento térmico do dosímetros de LiF:Mg,Ti consistiu de um período de uma hora a uma temperatura de $400^{\circ} \mathrm{C}$ no forno e duas horas na estufa a uma temperatura de $100^{\circ} \mathrm{C}$, com o objetivo de eliminação dos picos térmicos inerentes a baixas temperaturas.

\subsubsection{Curva de resposta TL em função da dose}

A irradiação dos dosímetros para a obtenção da curva TL em função da dose foi realizada no LCI - IPEN/CNEN-SP com o auxílio do aparelho de raios X para calibração em radiodiagnóstico (padrão secundário) e do simulador cúbico de PMMA preenchido com água.

Para a obtenção da curva de resposta TL em função da dose foram utilizados 9 dosímetros de $\mathrm{CaSO}_{4}$ :Dy (posicionados nos seus respectivos porta-dosímetros, demonstrado na figura 14, com os filtros de chumbo, chumbo furado e filtro de plástico) para cada um dos seguintes valores de dose: 1,0; 2,0; 5,0 e 10 mGy. O controle do tempo de irradiação, tensão do tubo $(\mathrm{kV})$, bem como o cálculo do tempo de irradiação para o cálculo do kerma de entrada na superfície (doses) foram obtidos pelo software National Instruments Lab VIEW 7.0. O valor de $50 \mathrm{kV}$ foi escolhido pela sua energia efetiva ser próxima a da energia efetiva do controle de qualidade do equipamento utilizado.

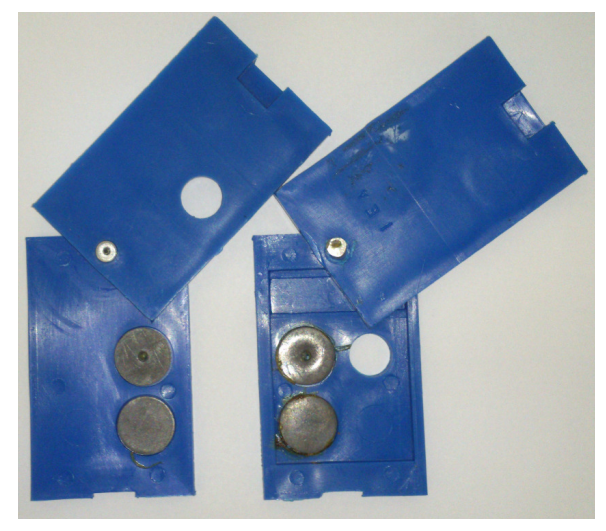

Figura 14 - Porta dosímetro com os três tipos de filtros. 
O mesmo procedimento foi realizado com os dosímetros tipo $\mathrm{LiF}: \mathrm{Mg}$, Ti, estes por sua vez não foram posicionados em nenhum sistema de porta-dosímetro, como mostrada na figura 15. Estes foram embalados em plástico em grupos de 10 dosímetros. Para a curva resposta TL em função da dose foram utilizados 10 dosímetros para cada valor de dose: 1,$0 ; 2,0 ; 5,0$ e 10 mGy.

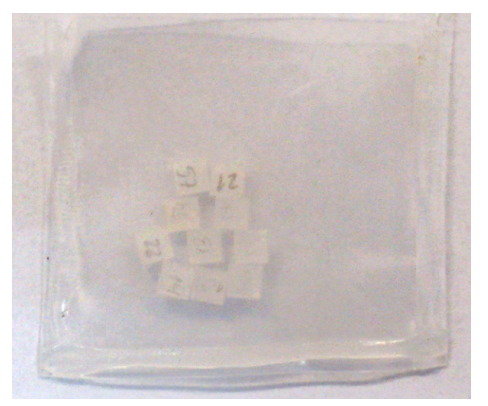

Figura 15 - Dosímetro de LiF:Mg,Ti embalados para serem utilizados nas irradiações

\subsubsection{Aquisição dos dados e irradiação dos dosímetros}

Os exames radiográficos monitorados foram realizados no Hospital Veterinário Dr. Halim Atique no Setor Radiologia da UNIRP.

Para o procedimento de abdômen são realizadas aquisições de uma ou duas radiografias, sendo uma latero-lateral e uma ventro-dorsal. Para aquisições de radiografia de tórax são realizadas de uma à três radiografias, sendo duas latero-lateral e uma ventrodorsal. A figura 16 ilustra o posicionamento correto dos animais nas duas projeções.

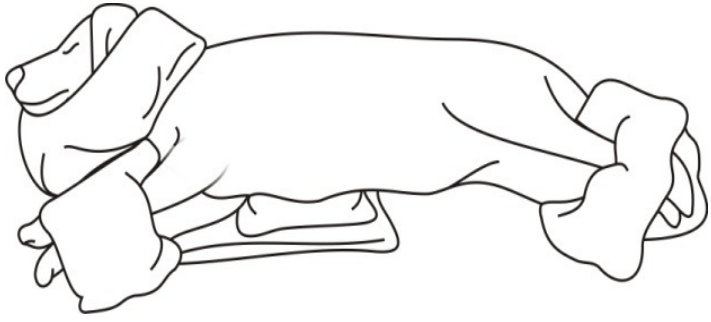

(a)

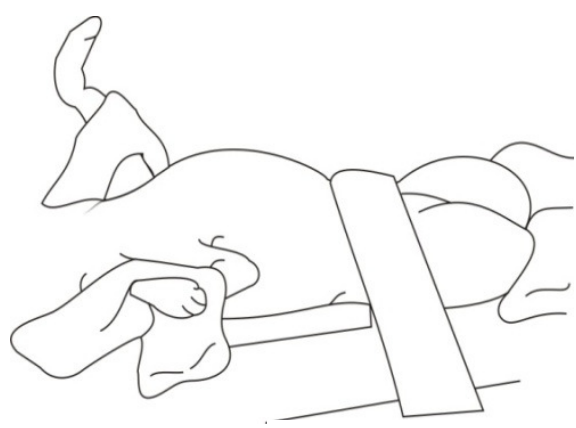

(b)

Figura 16: (a) Posicionamento latero-lateral e (b) posicionamento ventro-dorsal dos animais para a realização da radiografia. 
Foram monitorados 11 exames de abdômen e 14 exames de tórax de cachorros de raças distintas. Durante os exames foram anotados os valores das espessuras das duas projeções (latero-lateral e ventro-dorsal) com o auxílio de um espessômetro e, com a trena foi possível verificar a distância fonte-superfície de entrada da pele do animal. Ainda com auxílio da trena foi verificado o tamanho de campo utilizado para a realização das radiografias. Foram registrados também os valores de $\mathrm{kV}$ (tensão) e mAs (rendimento do tubo) de cada exame, pois cada animal tem um protocolo próprio, os quais foram utilizados para posterior simulação da irradiação dos exames. Convém ressaltar que os dosímetros foram mantidos em uma blindagem de chumbo antes e após a coleta dos exames (sendo dois porta-dosímetros utilizados para o grupo controle (Background)) garantindo, dessa forma, uma maior precisão nas medidas).

Após a obtenção de todos os dados dos exames radiográficos foram feitas as irradiações com o simulador utilizando o mesmo aparelho de raios X (marca Raicenter do Hospital Veterinário da UNIRP) e de um objeto simulador de látex ou polietileno com dimensões similares a cada animal, preenchido com água, assegurando a reprodutibilidade de todos os parâmetros citados acima. $\mathrm{O}$ esquema da figura 17 demostra como o simulador foi posicionado no centro da mesa de modo a ajustar corretamente o campo luminoso com a área dos dosímetros $\left(\mathrm{CaSO}_{4}: \mathrm{Dy}\right.$ e $\left.\mathrm{Li}: \mathrm{F}: \mathrm{Mg}, \mathrm{Ti}\right)$. Posteriormente, os dosímetros foram levados para o IPEN/CNEN-SP para a leitura das doses e análise dos resultados.

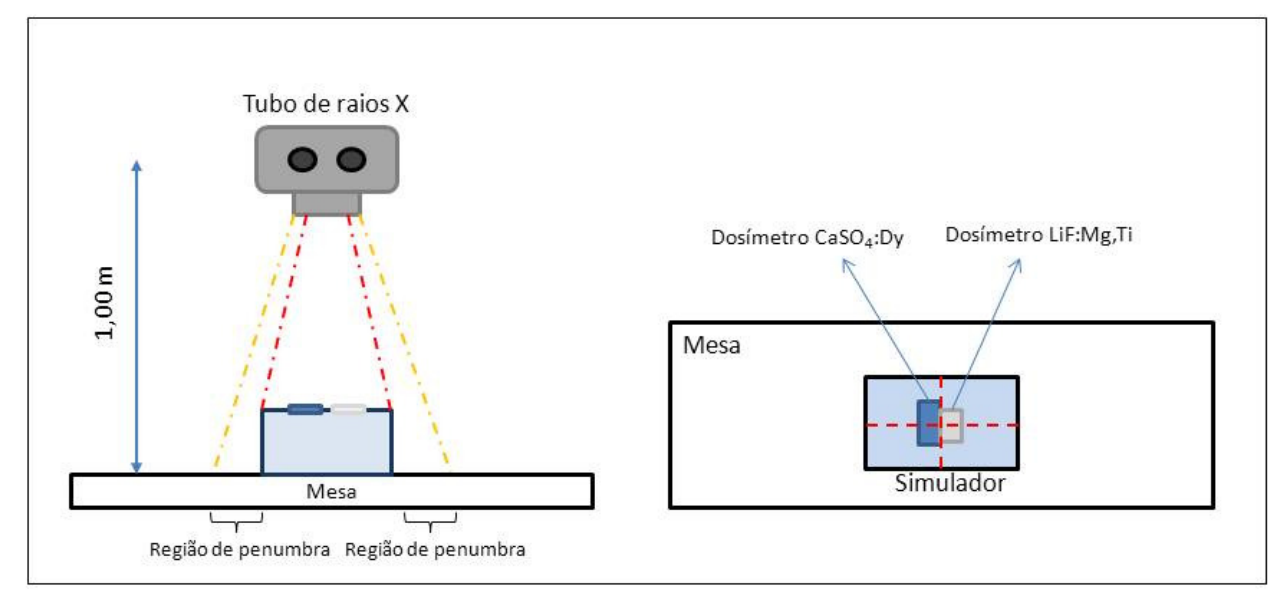

Figura 17 - Esquema para simular o arranjo experimental da reprodução de cada exame radiológico realizado. O esquema mostra o posicionamento do simulador e dos dosímetros utilizados em duas projeções (frontal e superior). 
4.4.4. Análise da radiação espalhada no ambiente e da dose individual dos indivíduos ocupacionalmente expostos

Para a avaliação da radiação espalhada no ambiente foram distribuídos 4 conjuntos de dosímetros em pontos específicos da sala, demostrados na figura 18 pela numeração de 1 à 4 do seguinte modo: (1) a frente da blindagem de chumbo que separa o comando do equipamento do equipamento em si; (2) atrás do equipamento de raios X; (3) localizado na entrada da sala e (4) na saída de emergência da sala.

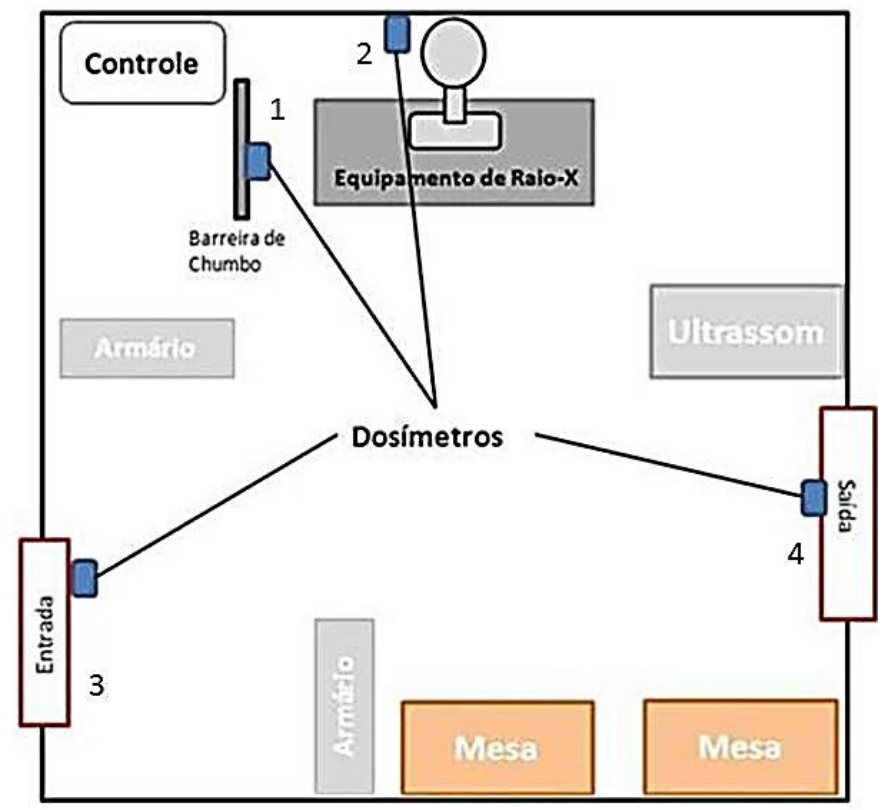

Figura 18 - Ilustração da sala de radiologia do Hospital Veterinário Dr. Halim Atique da UNIRP e o posicionamento dos dosímetros utilizados para monitoração da radiação espalhada.

Para a avaliação das doses recebidas pelos indivíduos ocupacionalmente expostos foram utilizados 2 dosímetros de tórax e 4 dosímetros tipo pulseira. Os dosímetros de tórax foram fixados no avental dos operadores pelo lado de fora do colete de chumbo (de uso obrigatório) na altura do peito, já os dosímetros tipo pulseira foram utilizados em todos que participam do exame radiográfico, tanto na contenção do animal como no auxílio com outro procedimento. A figura 19 ilustra como foram posicionados cada dosímetro. 


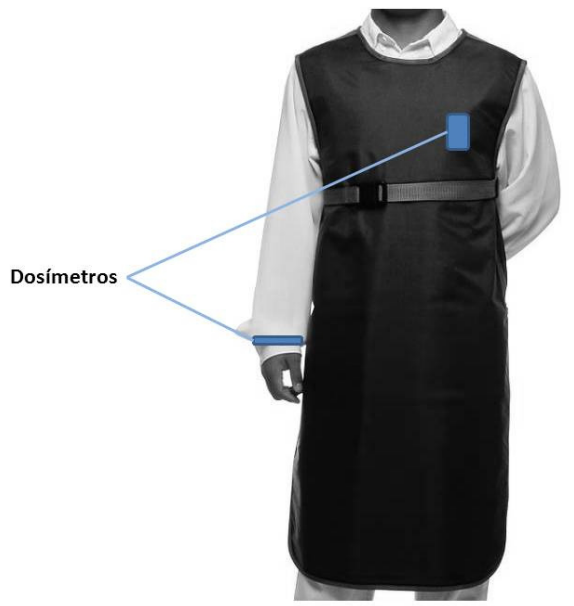

Figura 19 - Ilustração do posicionamento dos dosímetros de tórax e dosímetro pulseira.

\subsubsection{Análise de Resultados}

Obtidas as curvas de resposta TL em função da dose foram calculados o kerma de entrada da superfície do simulador de animal. Os resultados de kerma de entrada na superfície que serão apresentados a seguir serão tratados pelo nome de dose, conforme o item 3.5.4. nos permite tratar.

Os resultados dessa pesquisa são demonstrados em quatro etapas para a análise dos resultados dos procedimentos com os animais e trabalhadores. Na primeira etapa, os resultados são separados e demonstrados de acordo com o tamanho do animal, para animais submetidos a exames de abdômen, comparando as doses para cada porte de animal. A segunda etapa consistiu em avaliar os procedimentos de radiografias torácicas para animais de diferentes portes, comparando-as entre si. Na terceira etapa os resultados obtidos no Hospital Veterinário Dr. Halim Atique - UNIRP são comparados com os resultados obtidos no Hospital Veterinário da Universidade Estadual de São Paulo (UNESP-Botucatu) (VENEZIANI, 2009). Convém ressaltar que nas duas primeiras etapas os resultados de dose são comparados com dois tipos diferentes de dosímetros, $\mathrm{CaSO}_{4}$ :Dy e LiF:Mg,Ti utilizados.

Por último, os valores das doses de radiação secundária espalhada no ambiente, as doses recebidas pelos indivíduos ocupacionalmente expostos e pelos proprietários ou auxiliares (que realizaram a contenção dos animais) foram avaliados e comparados com as normas vigentes. 


\section{RESULTADOS E DISCUSSÕES}

\subsection{Curvas de resposta TL em função da dose e equações de ajustes}

Para a determinação das doses dos animais submetidos ao exame foram obtidas as curvas resposta TL em função da dose para os dois tipos de dosímetros $\left(\mathrm{CaSO}_{4}\right.$ :Dy e $\mathrm{LiF}: \mathrm{Mg}, \mathrm{Ti})$, conforme explicado no item 4.4.2.

As curvas de resposta TL em função da dose para dosímetros de $\mathrm{CaSO}_{4}$ :Dy foram obtidas para uma energia de $50 \mathrm{kV}$, conforme citado no item 4.4.2, e foram divididas em três curvas. A figura 20 apresenta a curva dose-resposta para os dosímetros irradiados na posição sob filtro de chumbo, a figura 21 apresenta os resultados para o filtro de chumbo com furo no centro e a figura 22 apresenta os resultados da filtragem com plástico.

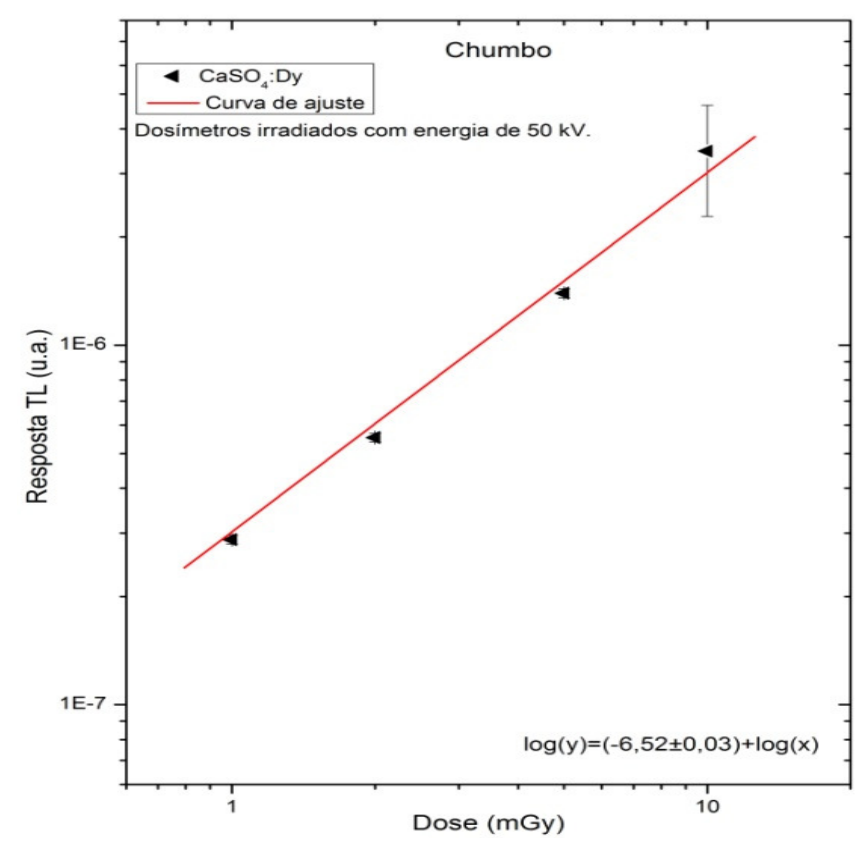

Figura 20 - Curva de resposta TL em função da dose utilizando filtro de chumbo com a equação do ajuste realizado. 


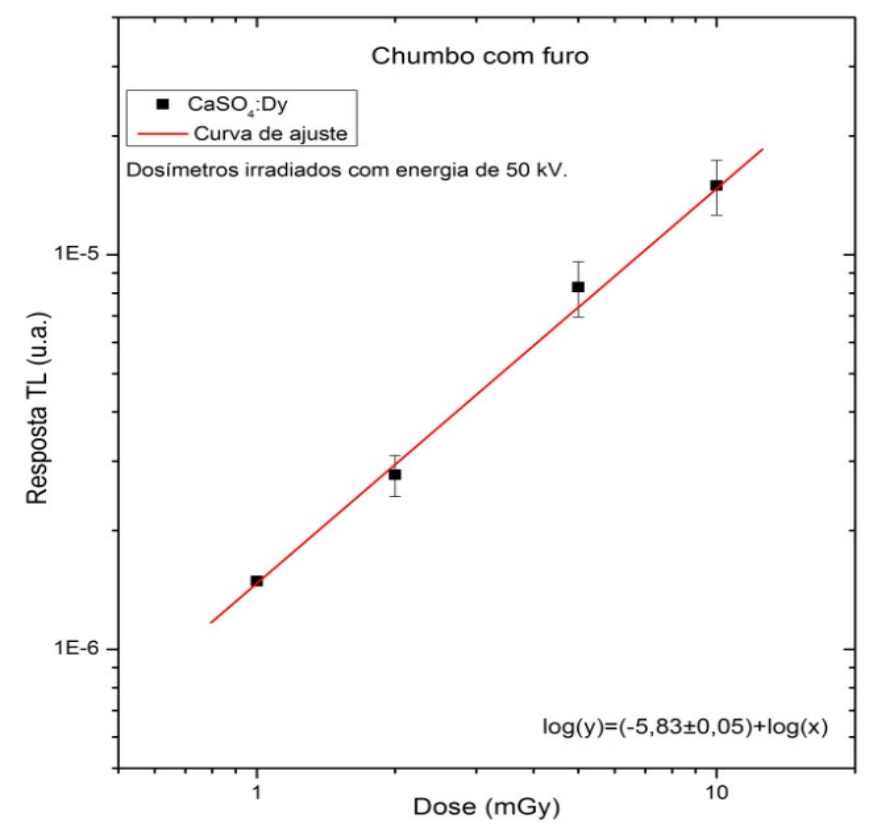

Figura 21 - Curva de resposta TL em função da dose com filtro de chumbo com furo com a equação do ajuste realizado.

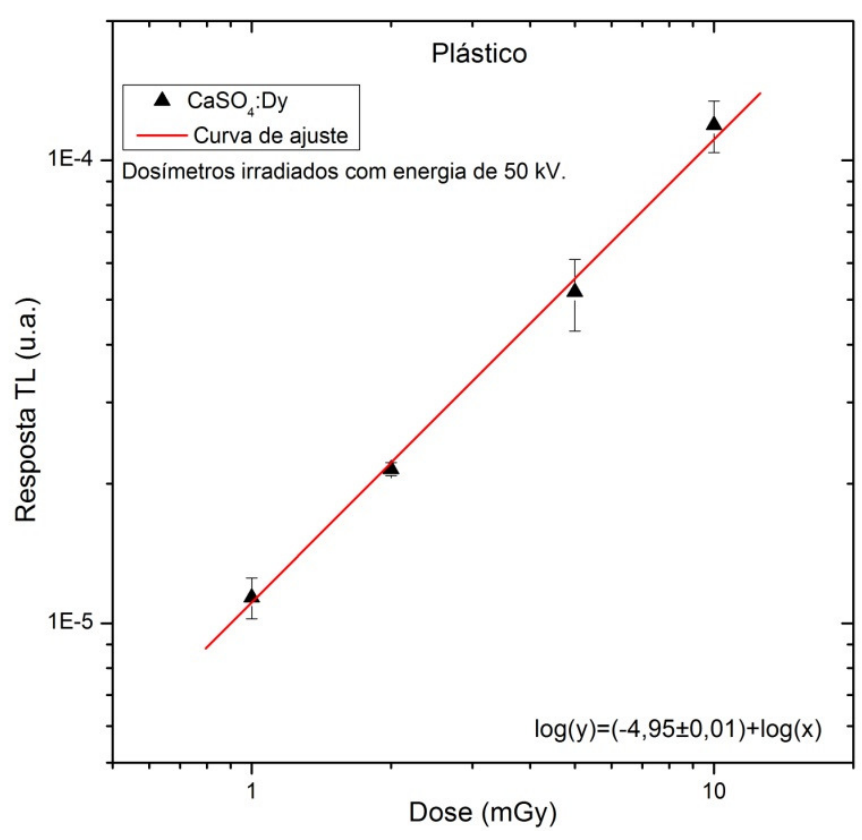

Figura 22 - Curva de resposta TL em função da dose com filtro de plástico com a equação do ajuste realizado.

Comparando-se as curvas resposta TL em função da dose (figura 23) pode ser observado que as três retas são paralelas, o que era esperado, uma vez que os coeficientes angulares são os mesmos. Isso comprova que os dosímetros respondem igualmente aos três tipos de filtragem. 


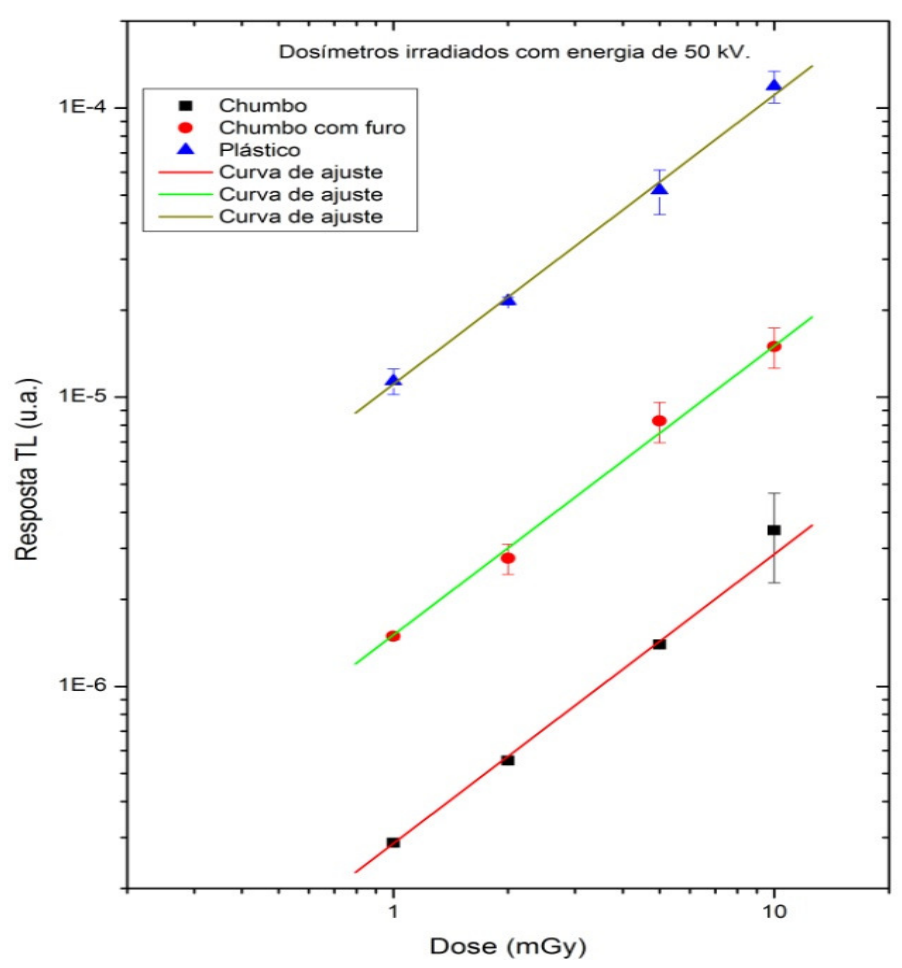

Figura 23 - Curva de resposta TL em função da dose para os três tipos de filtros.

As curvas de resposta TL em função da dose e equações da reta obtidas para o $\mathrm{CaSO}_{4}$ :Dy apresentadas nos gráficos 20-22, são de extrema importância para o cálculo das doses de cada animal. Cada curva resposta TL em função da dose tem sua peculiaridade por causa dos diferentes tipos de filtro, gerando três curvas diferentes e independentes, porém na figura 23 podemos observar que todas as retas são paralelas, demonstrando que a grande diferença entre elas é o sinal TL decorrente de cada tipo de filtragem (chumbo, chumbo com furo e plástico), consequência da interação fotoelétrica nesse intervalo de energia.

Para a comparação entre as doses determinadas pelos dois tipos de dosímetros foi obtida a curva resposta TL em função da dose para os dosimetros LiF:Mg,Ti, apresentada na figura 24. Esse procedimento foi realizado conforme já citado no item 4.4.2. 


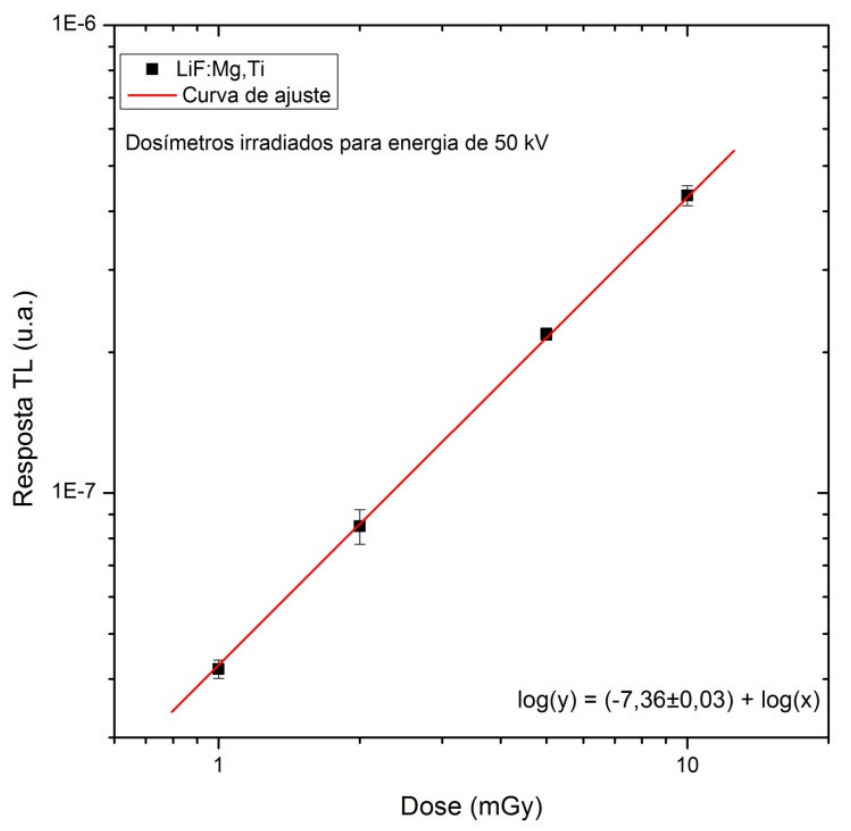

Figura 24 - Curva de resposta TL em função da dose para os dosímetros de LiF:Mg,Ti com a equação de ajuste.

A curva de resposta TL em função da dose e a equação para dosímetro LiF:Mg,Ti foi apresentada na figura 24 e teve por finalidade calcular as doses do mesmo procedimento já realizado com os dosímetros de $\mathrm{CaSO}_{4}$ :Dy (que apresentam dependência energética) e dosímetros de LiF:Mg,Ti (que apresenta resposta independente da energia), possibilitando assim a intercomparação dos resultados.

\subsection{Dose em animais submetidos a exame de abdômen}

Com as curvas de resposta TL em função da dose e equações de ajuste, apresentadas nas figuras de 20-22 e na figura 24, foi possível determinar a dose de cada animal submetido ao procedimento radiológico. Vale ressaltar que no trabalho em questão foi adotado a palavra dose como termo genérico para kerma de entrada na superfície, o qual a TRS-n457 faz sugestão para tal procedimento.

A primeira etapa do trabalho foi calcular as doses de animais submetidos a exames de abdômen. Para isso dividiu-se em três grupos: pequeno, médio e grande porte (de acordo com o tamanho de campo utilizado). Todos os protocolos dos exames estão disponíveis em anexo, os dados foram apresentados em gráficos para melhor visualização. 
A figura 25 apresenta as doses para animais de pequeno porte submetidos a exames de abdômen.

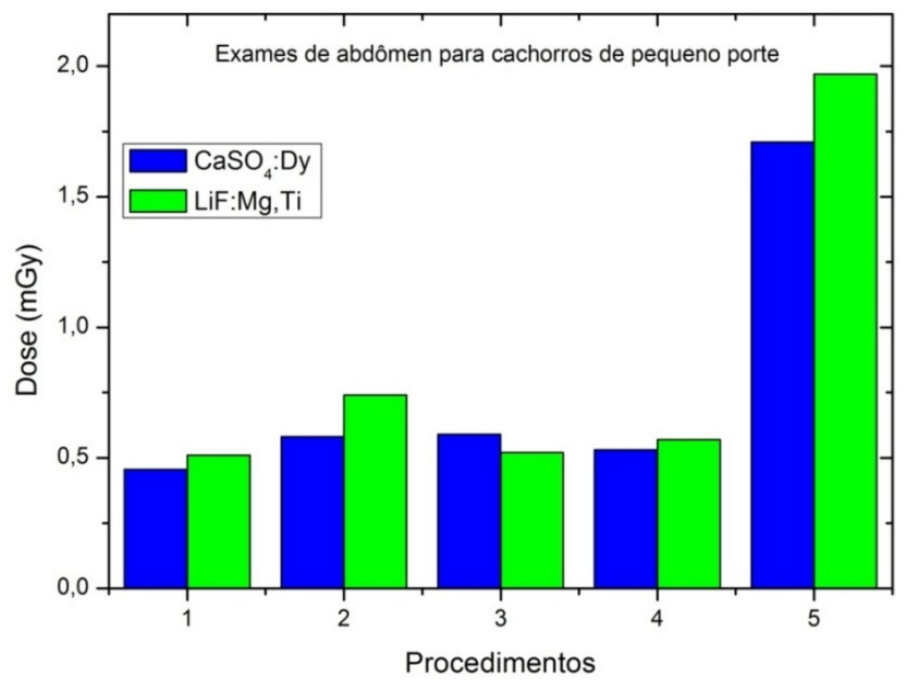

Figura 25 - Doses de entrada na pele de animais de pequeno porte para exames de abdômen calculados com dosímetros de $\mathrm{CaSO}_{4}$ :Dy e LiF:Mg,Ti.

De acordo com as doses avaliadas na figura 25 a dose média recebida por um animal de pequeno porte foi de 0,77 $\pm 0,52 \mathrm{mGy}\left(\mathrm{CaSO}_{4}: \mathrm{Dy}\right)$ e 0,84 $\pm 0,54 \mathrm{mGy}$ (LiF:Mg,Ti), sendo que as doses mínimas foram de 0,45 mGy $\left(\mathrm{CaSO}_{4}: \mathrm{Dy}\right)$ e 0,51 mGy (LiF:Mg,Ti) e as doses máximas foram de 1,71 mGy (CaSO 4 :Dy) e 1,87 mGy (LiF:Mg,Ti).

A figura 26 apresenta as doses para procedimentos de abdômen realizados em animais de médio porte.

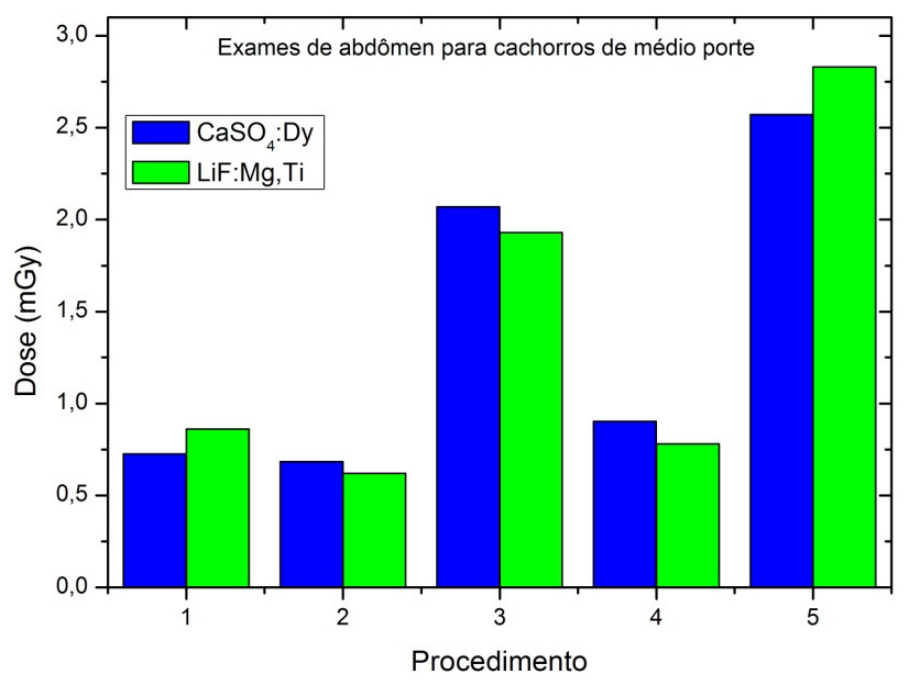

Figura 26 - Dose de entrada na pele para animais de médio porte submetido a exames de abdômen calculados com os dosímetros de $\mathrm{CaSO}_{4}$ :Dy e LiF:Mg,Ti. 
As doses médias calculadas para animais de médio porte em exames de abdômen

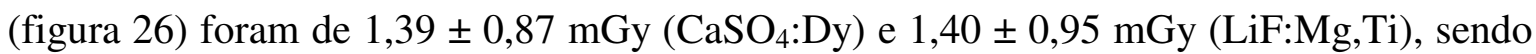
as doses mínimas de 0,68 mGy $\left(\mathrm{CaSO}_{4}: \mathrm{Dy}\right)$ e 0,62 mGy (LiF:Mg,Ti) e as doses máximas 2,57 mGy $\left(\mathrm{CaSO}_{4}: \mathrm{Dy}\right)$ e 2,83 mGy (LiF:Mg,Ti). Analisando os resultados é possível notar um aumento da dose de animais de pequeno porte para animais de médio porte.

A figura 27 apresenta o cálculo de dose para os dois tipos de dosímetros realizado em exames de cachorros de grande porte.

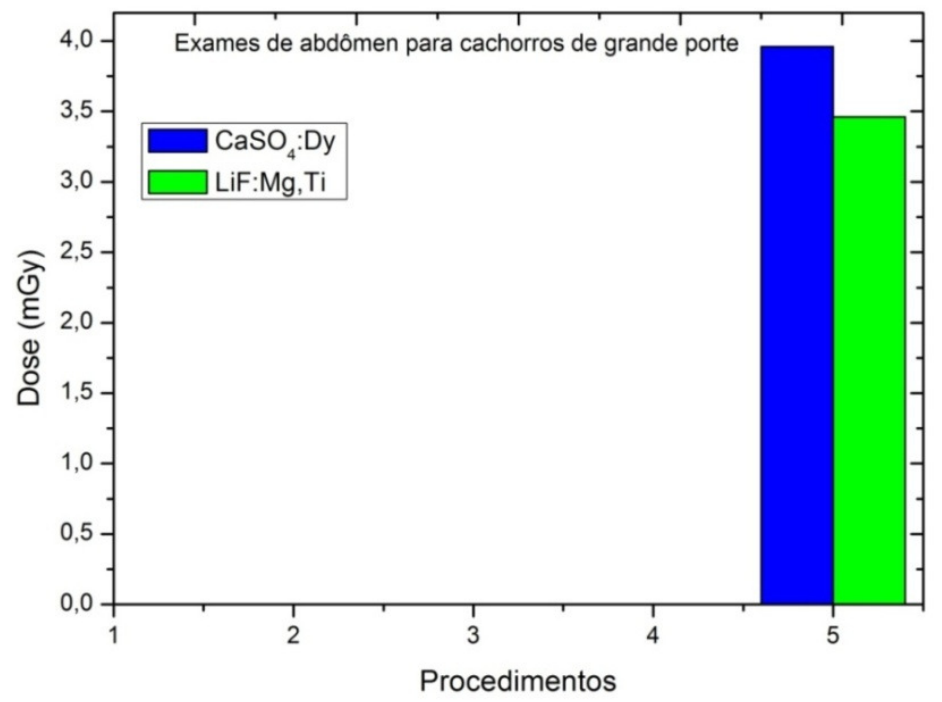

Figura 27 - Dose de entrada na pele para animais de grande porte submetidos a exames de abdômen calculados com os dosímetros de $\mathrm{CaSO}_{4}$ :Dy e $\mathrm{LiF}: \mathrm{Mg}, \mathrm{Ti}$.

Os animais de grande porte acabam recebendo doses mais altas, o que é observado na figura 27, cuja doses são de 3,96 mGy (CaSO $4: D y)$ e 3,46 mGy (LiF:Mg,Ti). Animais de grande porte são poucos frequentes para exames de abdômen, mas nota-se o aumento da dose em relação a animais médios.

A figura 28 apresenta o resultado de todos os procedimentos reproduzidos para exames radiológicos de abdômen dos animais avaliados nesse estudo. 


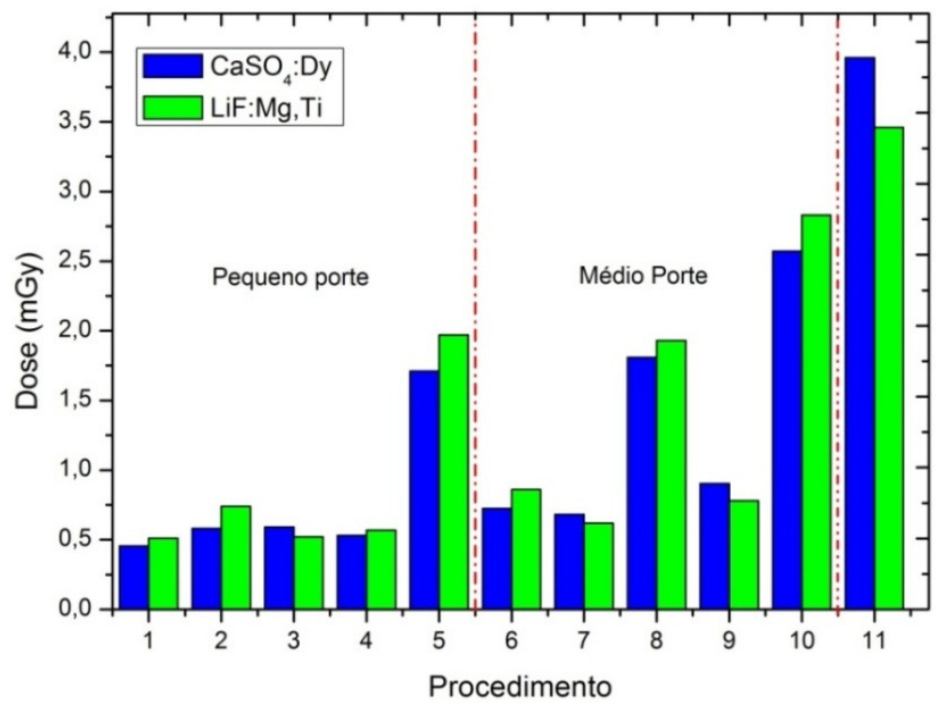

Figura 28 - Dose de entrada na pele para exames de abdômen realizado no Hospital Veterinário Dr. Halim Atique no setor de radiologia da UNIRP.

A relação entre o aumento da dose e o tamanho do animal pode ser observado na figura 28, na qual foram expostos todos os procedimentos realizados para os dois tipos de dosímetros. Esse aumento já era esperado, uma vez que, animais maiores necessitam de protocolos diferentes com, por exemplo: aumento do $\mathrm{kV}$, ou aumento do mAs ou pela distância entre o tubo e o abdômen do animal.

Convém ressaltar que não existe referência na literatura sobre limites de dose permissíveis em animais, porém um ser humano padrão em um procedimento similar tem como referência uma dose de 10 mGy (ANVISA, 1998). Considerando esse valor como referência todas as doses encontram-se abaixo desse limite.

Na figura 29 os resultados desses procedimentos são apresentados na ordem de necessidade de repetição, ou seja, se o exame foi realizado mais de uma vez ou apenas uma. 


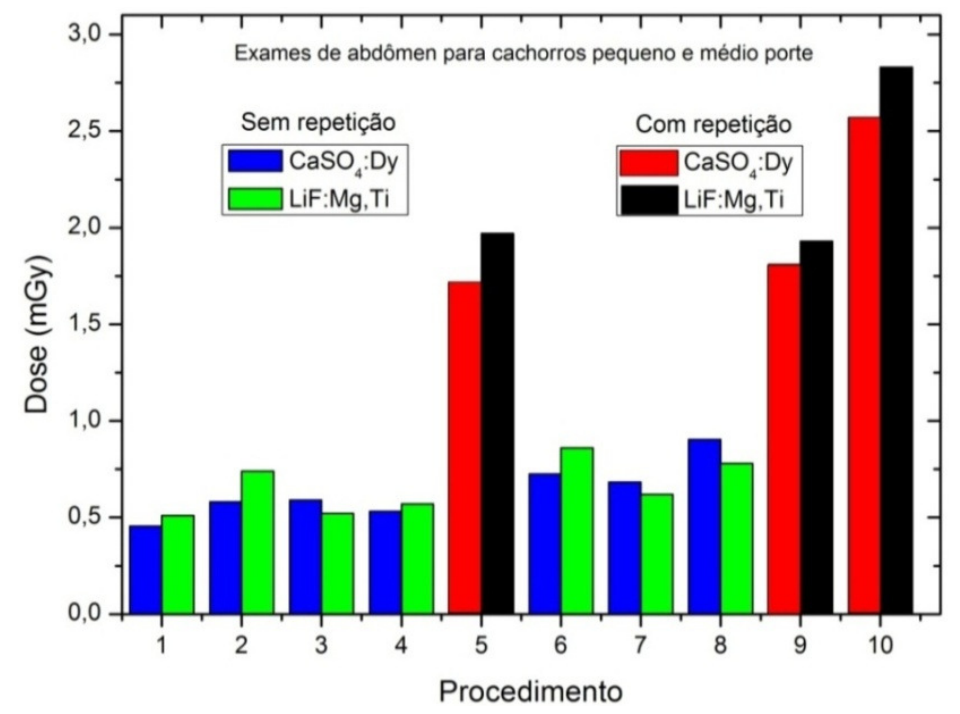

Figura 29 - Exames de abdômen para animais de pequeno e médio porte, demonstrando a diferença entre procedimentos com e sem repetição.

Pode ser observado o aumento de dose para animais submetidos a exames de abdômen com necessidade de repetição. Nota-se que a dose teve um aumento considerável chegando a 1,71 mGy $\left(\mathrm{CaSO}_{4}: \mathrm{Dy}\right)$ e 1,87 mGy (LiF:Mg,Ti) para o animal de pequeno

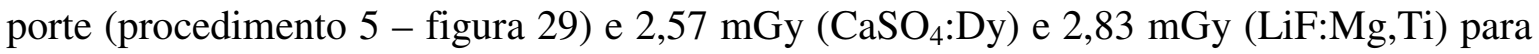
animal de médio porte (procedimento 10 - figura 29). Normalmente, as repetições são decorrentes da movimentação involuntária do animal ou por falha na técnica empregada, que são os casos dos procedimentos 5, 9 e 10 da figura 29. As variações observadas para o procedimento com repetições são de $\pm 216,7 \%$ ( $\left.\mathrm{CaSO}_{4}: \mathrm{Dy}\right)$ e $\pm 222,4 \%$ (LiF:Mg,Ti) e de $\pm 201,2 \%\left(\mathrm{CaSO}_{4}: \mathrm{Dy}\right)$ e $\pm 217,3 \%(\mathrm{LiF}: \mathrm{Mg}, \mathrm{Ti})$ para animais de pequeno e médio porte, respectivamente.

\subsection{Dose em animais submetidos a exames de tórax}

A segunda etapa do trabalho foi avaliar as doses de animais submetidos a radiografias torácicas no Hospital Veterinário Dr. Halim Atique.

Os exames de tórax podem ser realizados com uma radiografia (uma projeção) até três radiografias (duas projeções latero-laterais e uma ventro-dorsal). Os dados a seguir demonstram as doses recebidas em cada procedimento torácico. A figura 30 apresenta os resultados das doses de cachorros de pequeno porte. 


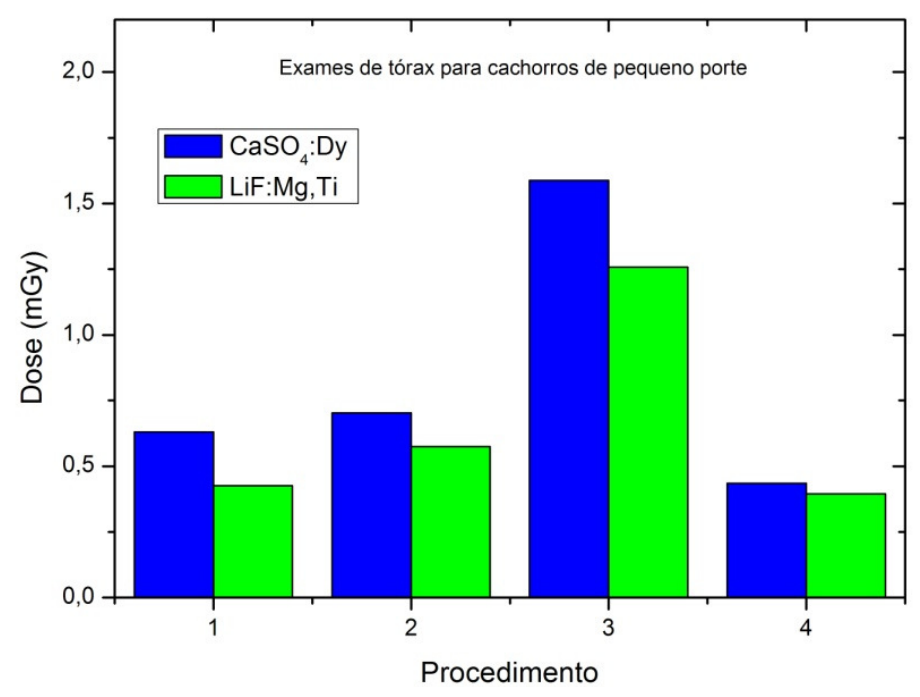

Figura 30 - Dose de entrada na pele de animais de pequeno porte para exames de tórax calculados com dosímetros de $\mathrm{CaSO}_{4}: \mathrm{Dy}$ e $\mathrm{LiF}: \mathrm{Mg}$,Ti.

Na figura 30 observa-se que a dose média para cachorros radiografados foi de 0,83 \pm 0,51 mGy $\left(\mathrm{CaSO}_{4}: \mathrm{Dy}\right)$ e 0,66 \pm 0,40 mGy ( $\left.\mathrm{LiF}: \mathrm{Mg}, \mathrm{Ti}\right)$, sendo as doses mínimas 0,44 mGy $\left(\mathrm{CaSO}_{4}: \mathrm{Dy}\right)$ e 0,39 mGy (LiF:Mg,Ti) e doses máximas de 1,58 mGy $\left(\mathrm{CaSO}_{4}: \mathrm{Dy}\right)$ e 1,25 mGy (LiF:Mg,Ti).

A figura 31 apresenta as doses para procedimentos de tórax realizados em animais de médio porte.

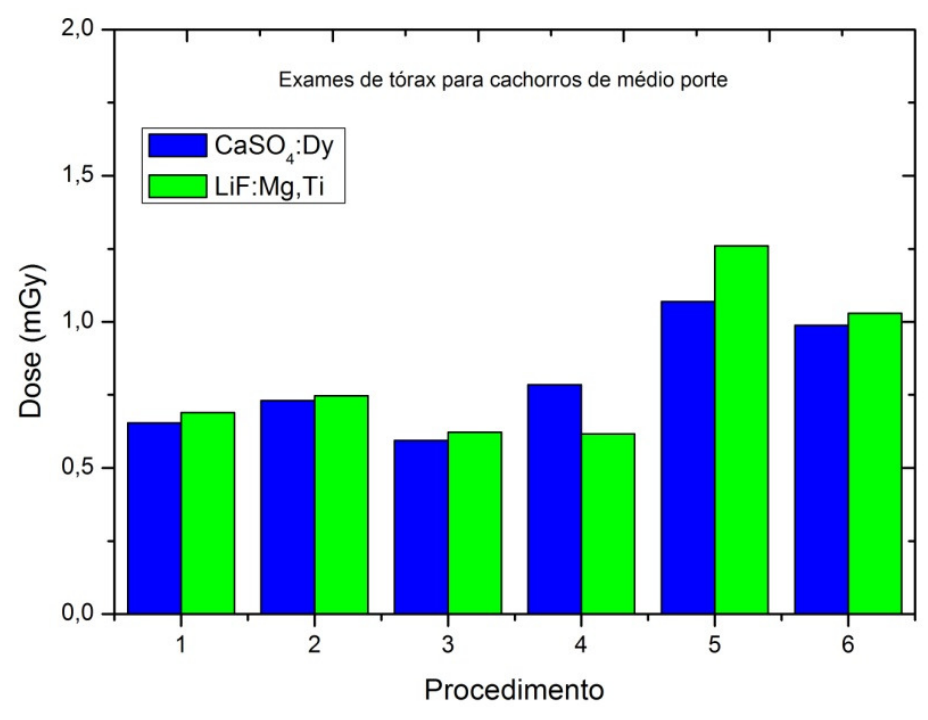

Figura 31 - Dose de entrada na pele para animais de médio porte submetido a exames de tórax calculados com os dois tipos de dosímetros de $\mathrm{CaSO}_{4}$ :Dy e $\mathrm{LiF}: \mathrm{Mg}, \mathrm{Ti}$.

A dose para animais de médio porte (figura 31) teve um pequeno aumento, como já

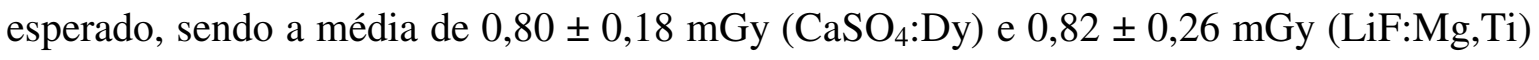


e doses mínimas e máximas de 0,59 mGy (CaSO 4 :Dy), 0,61 mGy (LiF:Mg,Ti) e 1,07 mGy $\left(\mathrm{CaSO}_{4}: \mathrm{Dy}\right)$ e 1,26 mGy (LiF:Mg,Ti), respectivamente.

A figura 32 apresenta o cálculo de dose para diferentes exames de tórax realizados em exames de cachorros de grande porte.

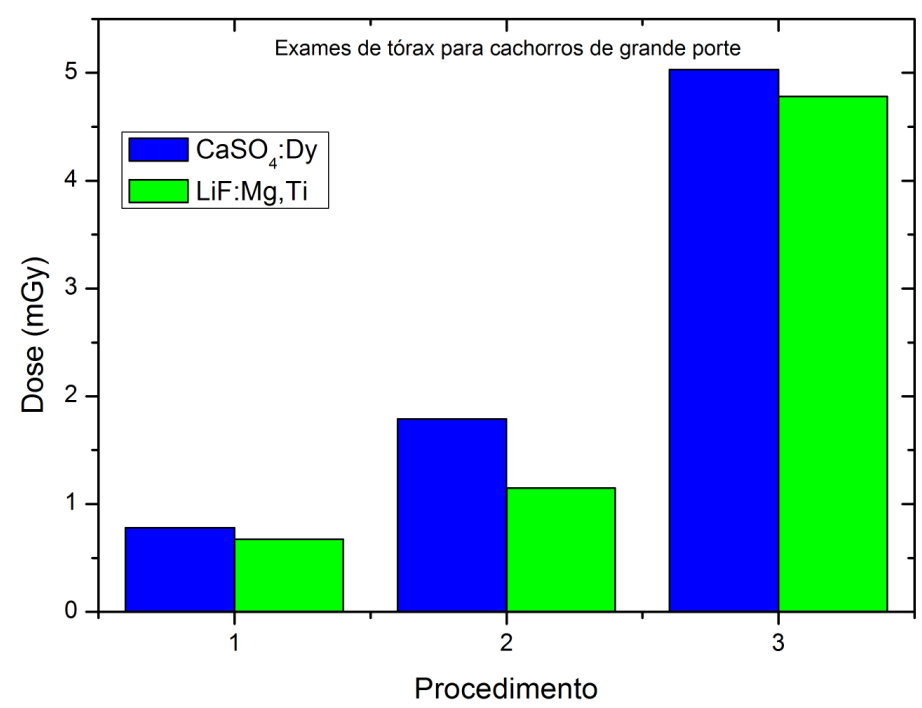

Figura 32 - Dose de entrada na pele para animais de médio porte submetido a exames de tórax calculados com diferentes tipos de dosímetro $\mathrm{CaSO}_{4}: \mathrm{Dy}$ e $\mathrm{LiF}: \mathrm{Mg}, \mathrm{Ti}$.

As doses mínimas e máximas referente aos exames de tórax para os animais de grande porte foram de 0,78 $\mathrm{mGy}\left(\mathrm{CaSO}_{4}: \mathrm{Dy}\right)$ e 0,69 mGy (LiF:Mg,Ti) e 5,03 mGy (CaSO $4: D y)$ e 4,78 mGy (LiF:Mg,Ti), respectivamente.

A figura 33 apresenta o resultado de todos os procedimentos reproduzidos para exames radiológicos de tórax dos cachorros avaliados. 


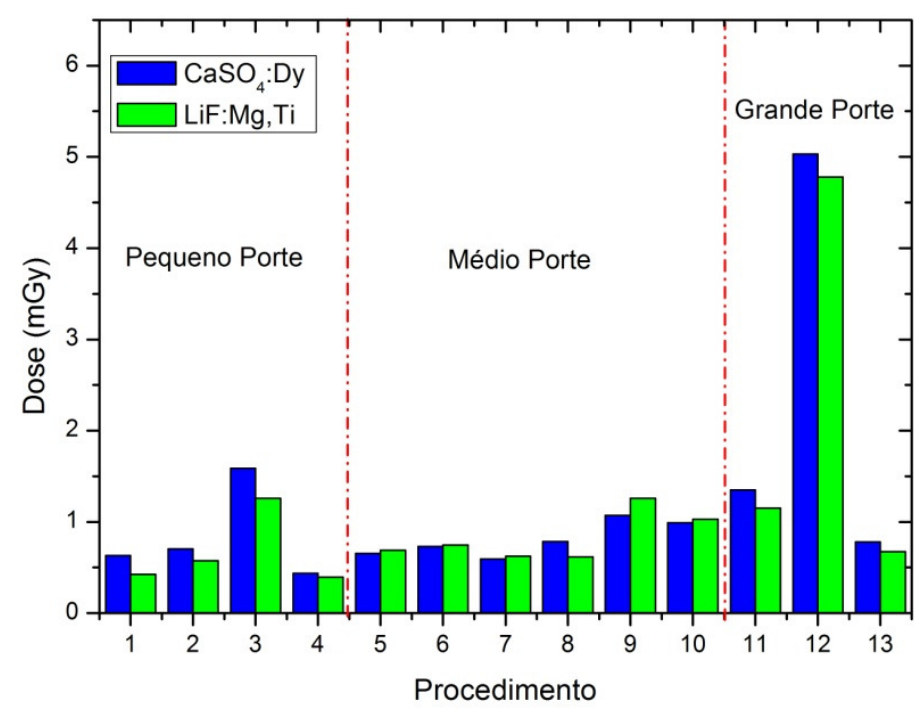

Figura 33 - Dose de entrada na pele para exames de tórax realizado no Hospital Veterinário Dr. Halim Atique no setor de radiologia da UNIRP.

Os exames de radiografias de tórax de cachorro normalmente são realizados em duas ou três projeções, por isso as doses podem ser um pouco mais elevadas se comparar com outros procedimentos. Na figura 33 pode-se observar o conjunto de procedimentos que foram realizados no Hospital Veterinário Dr. Halim Atique. Observa-se o aumento de dose para animais maiores, o que era previsto pelo aumento da técnica ( $\mathrm{kVp}$ ou mAs) para animais maiores.

Vale ressaltar que não existe referência na literatura sobre limites de dose permissíveis em animais, porém para um ser humano padrão, em um procedimento similar, tem com referência uma dose de 2,3 mGy (considerando uma projeção latero-lateral e duas projeções antero-posteriores, descrita na PORTARIA 453 da Secretária de Vigilância Sanitária (ANVISA, 1998).

Nota-se em todos os gráficos as diferenças entre as doses obtidas por dosímetros de $\mathrm{CaSO}_{4}$ :Dy e LiF:Mg,Ti, essa diferença pode ser justificada pela estatística pobre no caso do $\mathrm{CaSO}_{4}$ :Dy que foi utilizado um porta dosímetro por procedimento, enquanto o Li:F,Mg,Ti foram utilizados seis dosímetros por procedimento. Outra diferença pode ser o incerteza tolerável de $5 \%$ na repetibilidade de cada dosímetro.

\subsection{Comparação entre hospitais distintos}

As figuras de 34-36 apresentam os dados das doses de animais submetidos a exames de tórax irradiados no Hospital Veterinário da Faculdade de Medicina Veterinária 
e Zootecnia (FMVZ) da UNESP-Botucatu (VENEZIANI, 2009) e Hospital Veterinário Dr

Halim Atique. Para esses resultados foram utilizados apenas dosímetros de $\mathrm{CaSO}_{4}$ :Dy.

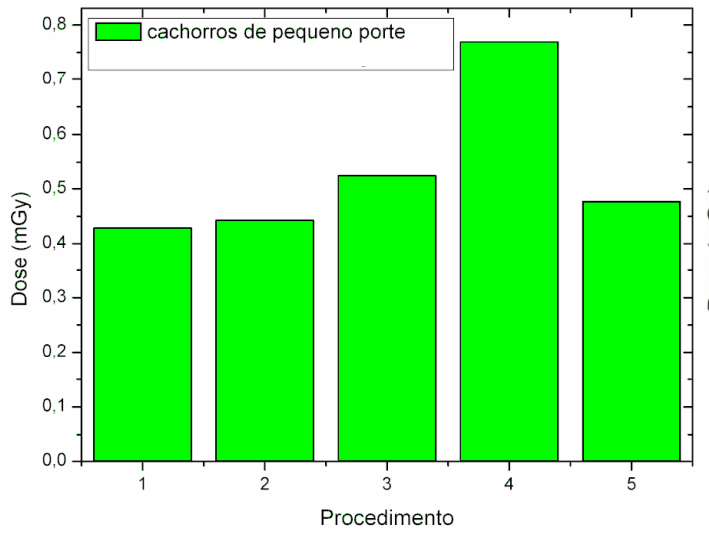

(a)

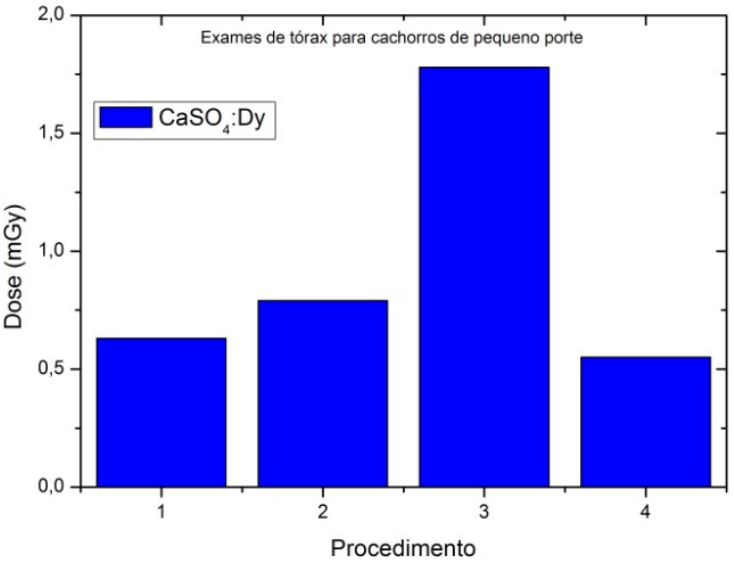

(b)

Figura 34 - Doses de entrada na pele de animais de pequeno porte para exames de tórax realizados no (a) Hospital Veterinário da UNESP-Botucatu e (b) Hospital Dr. Halim Atique.

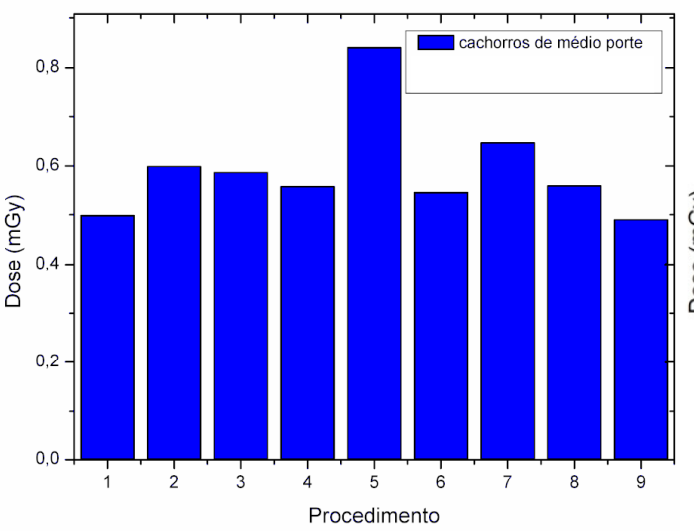

(a)

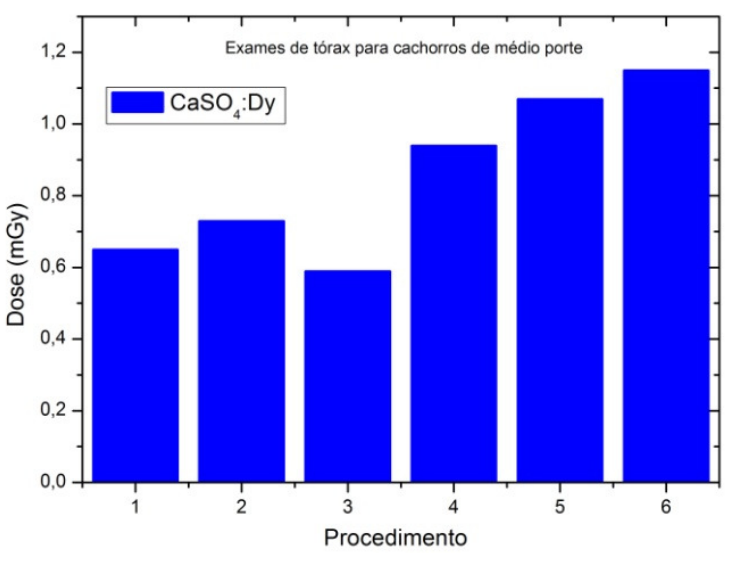

(b)

Figura 35 - Doses de entrada na pele de animais de médio porte para exames de tórax realizados no (a) Hospital Veterinário da UNESP-Botucatu e (b) Hospital Dr. Halim Atique. 


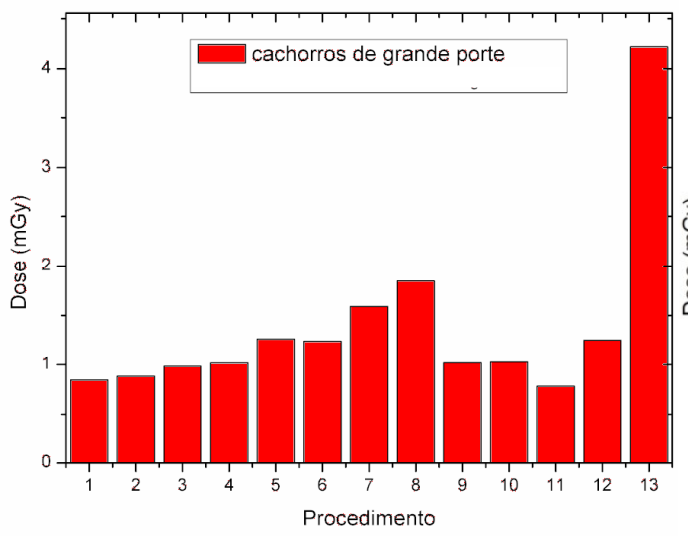

(a)

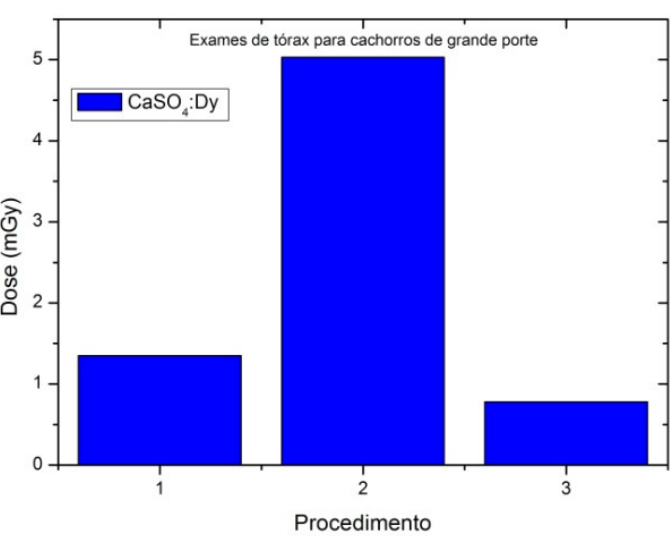

(b)

Figura 36 - Doses de entrada na pele de animais de grande porte para exames de tórax realizados no (a) Hospital Veterinário da UNESP-Botucatu e (b) Hospital Dr. Halim Atique.

A terceira etapa da análise de dados é a intercomparação entre procedimentos semelhantes (radiografias de tórax), porém em hospitais distintos. Nessa etapa foram analisadas apenas as doses calculadas com o dosímetro de $\mathrm{CaSO}_{4}: \mathrm{Dy}$. As doses médias dos animais de pequeno porte para os hospitais Dr. Halim Atique -UNIRP e FMVZ-UNESP Botucatu foram de 0,83 $\pm 0,51 \mathrm{mGy}$ e 0,52 $\pm 0,13 \mathrm{mGy}$, respectivamente. Já para os cachorros de médio porte as DEPs médias foram de 0,80 \pm 0,18 mGy no Hospital da UNIRP e 0,59 $\pm 0,10 \mathrm{mGy}$ no Hospital da UNESP. Finalmente, para animais de grande porte as doses médias é foram de 2,38 $\pm 2,30 \mathrm{mGy}$ e $1,35 \pm 0,95 \mathrm{mGy}$ no Hospital da UNIRP e Botucatu, respectivamente.

Essa diferença de dose entre os hospitais pode ser justificada pela diferença de equipamentos e técnicas que são utilizados nos setores de Radiologias de ambas as universidades, porém, convém ressaltar que os serviços das duas instituições passam por controles de qualidade anuais em seus equipamentos, de forma a cumprir as determinações da PORTARIA 453 da ANVISA. Dessa forma, os equipamentos utilizados nesse estudo estão dentro das normas vigentes.

\subsection{Radiação espalhada na sala}

A quarta e última etapa da pesquisa, foi avaliar a dose de radiação espalhada no ambiente, por definição equivalente de dose ambiental, que é definida por $\mathrm{H}^{*}$ segundo a resolução da CNEN 102 (CNEN, 2010). 
Os dosímetros foram posicionados em pontos da sala, conforme a figura 17 no item 4.4.4 já demostrada.

As doses de radiação aferidas pela Gerência de Metrologia das Radiações (GMRIPEN), utilizando uma leitora de rotina modelo Harshaw 5500, avaliou as dose nos pontos 4,3 e 1 (conforme a figura 18) como desprezível, ou seja, abaixo da radiação ambiente ou BG, não apresentando riscos a proprietários, estagiários ou técnicos nessas regiões, porém não é recomendada a permanência desnecessária de pessoas na sala de radiografia.

A região mais próxima ao tubo de raios $X$ (figura 18 - dosímetro 2) apresentou equivalente de dose ambiental de 0,50 mSv. Apesar de apresentar dose, o ponto 2 é uma localização da sala que não é frequentada por nenhuma pessoa e está muito próximo ao tubo de raios X. Vale ressaltar que o equipamento passa por controle de fuga de radiação do tubo anualmente, e que está de acordo com as normas vigentes.

\subsection{Doses individuais recebidas por trabalhadores e estagiários}

As doses em trabalhadores pela resolução CNEN No 102 é definida por $\mathrm{H}_{\mathrm{x}}$ e recebe o nome de dose individual (CNEN, 2010).

As doses individuais aferidas pela GMR para os trabalhadores e estagiários estão demonstradas na figura 37.

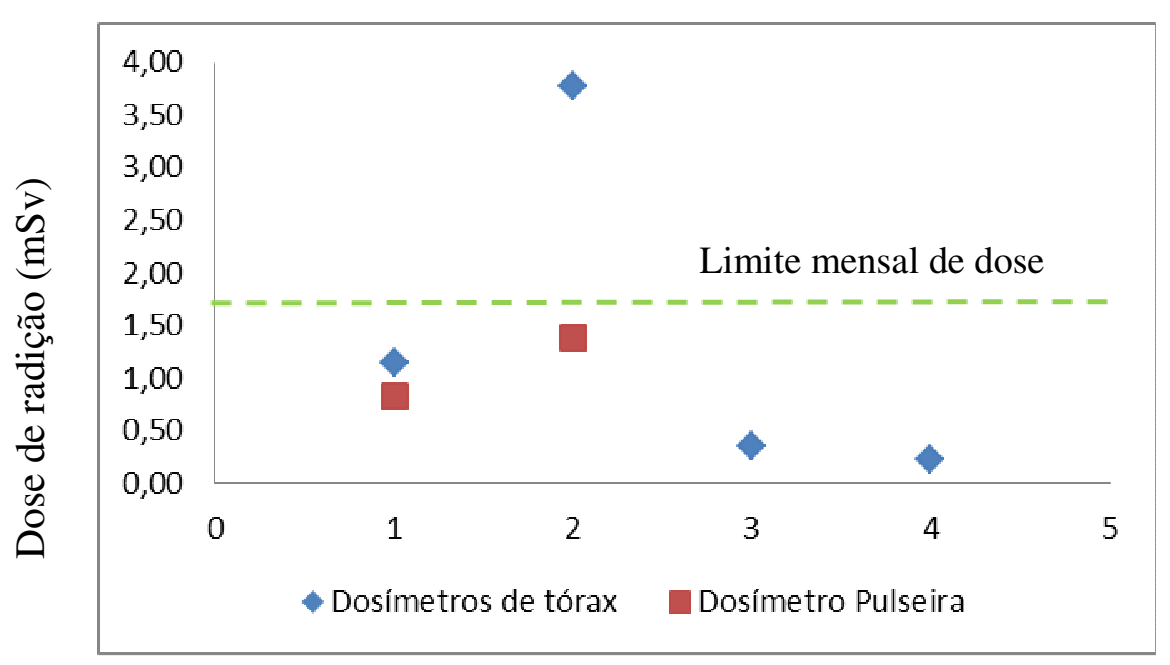

Figura 37 - Dose individual dos operadores (1 e 2) e estagiários (3 e 4). 
De acordo com a legislação vigente apresentada na tabela 1, o trabalhador não deve receber uma dose superior a $20 \mathrm{mSv}$ ao ano para medidas de corpo inteiro (em média 1,67 mSv ao mês) e não deve receber uma dose efetiva superior a $150 \mathrm{mSv} / \mathrm{ano}$ em extremidades.

Analisando os dados da figura 37, nota-se que o operador 2 recebeu uma dose individual acima da média no mês de novembro, para a medida do dosímetro de tórax. Esse resultado demonstrou um $\mathrm{H}_{\mathrm{x}}$ acima dos limites padrões e deve ser investigada pelos responsáveis do setor, para averiguar se o trabalhador cometeu algum erro de procedimento quanto à proteção radiológica (por exemplo: esquecer o dosímetro no feixe de radiação) ou se $H_{x}$ recebida por ele está realmente correta. É recomendado que seja observado o uso correto do dosímetro e os registros de históricos das doses dos meses anteriores e posteriores do operador 2. O operador 1 recebeu um $\mathrm{H}_{\mathrm{x}}$ dentro do limite permissível.

Para analisar os estagiários que ajudam no setor, foram utilizados os dosímetros pulseiras, conforme já citado no item 4.4.5, que apresentaram doses baixas de 0,35 e 0,23 mSv. Apesar dessas doses não terem excedido os limites permissíveis é imprescindível que todos utilizem os equipamentos de radioproteção para cada procedimento realizado e durante todo o expediente de trabalho.

\subsection{Incerteza das medidas}

Toda medida está sujeita a incertezas, por isso, temos que minimizar a maior quantidade de erros possíveis para que a medida seja razoavelmente confiável (ABNT, INMETRO, 2003).

As incertezas principais do tipo A são:

- Homogeneidade do feixe de raios X;

- Dispersão dos valores das medidas das respostas TLs realizadas na leitora TL

As incertezas do tipo B são:

- Erros no controle do tempo dos tratamentos térmicos dos DTLs;

- Erros no cálculo do tempo da irradiação dos DTLs;

- Erros na reprodução do posicionamento dos DTLs durante as irradiações; 
- Tempo de armazenamento dos DTLs na blindagem de chumbo, antes da execução da leitura da resposta;

- Erros dos equipamentos de radiodiagnósticos (tolerados pela ANVISA).

A incerteza do tipo B são desprezíveis comparadas com as do tipo A, com exceção do erro de posicionamento, que pode ser minimizado usando, por exemplo laseres para posicionamento.

As incertezas do tipo A podem ser minimizadas adotando um controle rigoroso da sensibilidade do lote de dosímetros (dentro de $\pm 5 \%$ ); Utilização de dosímetros de controle para cada medida realizada; desse modo, a incerteza de maior peso será a homogeneidade do feixe.

Uma estimativa da ordem de grandeza das incertezas do tipo A pode ser obtida a partir do desvio padrão das medidas obtidas com os dosímetros de LiF, onde foram utilizados 10 dosímetros para cada dose.

O valor estimado para as incertezas que envolve a irradiação dos dosímetros está na ordem de $2 \%$ (ABNT, INMETRO, 2003). 


\section{CONCLUSÕES}

- As doses médias obtidas para animais submetidos a exames radiográficos de abdômen foram de 0,80 mGy para animais de pequeno porte, de 1,39 mGy para animais de médio porte e de 3,71 para animais de grande porte.

- As doses médias para radiografias de tórax foram de 0,74 mGy para animais de pequeno porte, $0,81 \mathrm{mGy}$ para animais de médio porte e de $0,73 \mathrm{mGy}$ para animais de grande porte.

- Os resultados comparativos entres os hospitais demostraram que pode ocorrer diferenças de até $75 \%$ em relação às doses.

- $\mathrm{O}$ equivalente de dose ambiental referente a $\mathrm{H}^{*}$ não demonstraram valores anormais.

- A dose individual $\left(\mathrm{H}_{\mathrm{x}}\right)$ em trabalhadores e estagiários deve ser observada periodicamente para evitar dose acima do permitido, como a apresentada no trabalhador $2(3,72 \mathrm{mGy})$.

Os resultados obtidos indicam que é extremamente importante a avaliação das doses envolvidas na radiologia diagnóstica veterinária, tanto para o conhecimento das doses dos animais, como para serem usadas como parâmetro na avaliação das doses individuais de trabalhadores das Clínicas Veterinárias, que podem realizar vários procedimentos diários e também dos proprietários, uma vez que as doses podem exceder os limites anuais de dose vigentes no Brasil.

Convém ressaltar que ainda não existem doses de referência e nem estudos aprofundados sobre os limites de doses em animais domésticos, portanto, esta pesquisa representa um pequeno passo para que novas pesquisas sejam desenvolvidas.

Os valores encontrados confirmam também a necessidade de otimização dos procedimentos de radiologia diagnóstica veterinária para a redução das doses, de modo a mantê-las tão baixas quanto razoavelmente exequíveis (princípio ALARA). 


\section{Bibliografia}

ABNT, INMETRO. (2003). Guia para expressão da incerteza de medidas. Páginas 1-131. Rio de Janeiro - RJ, Brasil: Sindicato Nacional de editores de livros.

ANVISA. (01 de junho de 1998). Portaria 453 - . Diretrizes Básicas de Proteção Radiológica. ANVISA.

BITELLI, T. (2006). Física e dosimetria das radiações. São Paulo: Atheneu.

CAMERON, J. R., SUNTHARALINGAM, N., \& KENNEY, G. N. (1968). Thermoluminescent Dosimetry. Wisconsin: The Colonial Press Inc.

CAMPOS, L. L. (1998). Thermoluminescence of materials and its application on radiation dosimetry. Cerâmica, v. 44, n 290.

CAMPOS, V. D. (2005). Desenvolvimento e Avaliação de um novo porta detector/filtro para monitoramento termoluminescente com CaSO4 :Dy/PTFE. São Paulo: IPEN/CNEN.

CNEN No 102 - (2010). Coeficiente de dose para exposição do público. Rio de Janeiro-RJ

CNEN NN 3.01. (2011). Diretrizes Básicas de Proteção Radiológica. Rio de Janeiro-RJ

CURRY, T. S., DOWDEY, J. E., \& MURRY, R. C. (1990). Christensen's Physiscs of Diagnostic Radiology. Williams \& Wilkins.

FONSECA PINTO, A. C., IWASAKI, M., FIGUEIREDO, C. M., CORTOPASSI, S. R., \& STERMAN, F. A. (2007). tomografia computadorizada do tórax de cadelas portadoras de neoplasia malignas. II - Avaliação dos campos pulmonares. Braz. J. vet. Res. anim. Sci, pp. v. 44, n. 3, p. 174-182.

GARLAND, M. R., Lawler, L. P., Whitaker, B. R., Walker, I. D., Corl, F. M., \& Fishman, E. K. (2002). Modern CT Applications in Veterinary Medicine. Educatio Exhibit, vol. 22, No 1, pp 55-62. 
HERNÁNDEZ-RUIZ, L., JIMENEZ-FLORES, Y., RIVERAMONTALVO, T., ARIASCISNEROS, L., \& MÉNDEZ-AGUILAR, R. E. (21 de junho de 2012). Thermoluminescent Dosimetry in Veterinary Diagnostic Radiology. Applied Radiation and Isotopes, pp. v. 71 p 44-47.

IAEA, I. A. (2005). A handbook for teachers and students. Viena: IAEA.

IAEA, (2007). Dosimetry in diagnostic radiology: an international code of practice. Technical Reports Series $N^{\circ}$ 457. Vienna: IAEA.

ICRP. (2007). International Commission on Radiological Protection. Recommendations, Publication 103.

MARTINS, R. D. (dezembro de 1998). A descoberta dos raios X: O primeiro comunicado de Röntgen. Revista Brasileira de Ensino de Física, pp. vol. 20 no. 4, pag 373-390.

MCKEEVER, S. W. (1985). Thermoluminescence of Solids. Cambridge, England: Cambridge University Press.

McKEEVER, S., MOSCOVITCH, M., \& TOWNSEND, P. (1995). Thermoluminescence dosimetry materials: Properties and uses. . Ashford, Kent: Nuclear Technology Publishing.

NCRP Report 148. (2004). Radiation protection in veterinary medicine. National Council on Radiation Protection and Measurements. Bethesda.

NOUAILHETAS, Y. (2012). Radiações Ionizantes e a Vida. Acesso em 08 de dezembro de 2012, disponível em www.cnen.gov.br: www.cnen.gov.br

OBERHOFER, M., \& SCHARMANN, A. (1979). Applied Thermoluminescence dosimetry. . Ispra, Itália: Adam Hilger Ltd (Commission of the European Communities).

OKUNO, E., \& YOSHIMURA, E. M. (2010). Física das radiações. São Paulo: Oficina de Textos.

SAW, C. B. (2002). Foundation of Radiological Physics. Omaha: NE: CBSaw, Inc.

SEIFERT, H., LUPKE, M., NIEHAUS, H., \& MEYER-LINDENBERG. (2007). A. Radiation exposure of the pet owner during standardised X-ray diagnostic examinations of dogs and cats. . Berliner Und Munchener Tierarztliche Wochenschrift, pp. v.120, n. 5-6, p.251-259. 
SEIFERT, H., LUPKE, M., NIEHAUS, H., \& MEYER-LINDENBERG. (2008). A. Radiation exposure of the staff during standardised radiography of dogs and cats. Berliner Und Munchener Tierarztliche Wochenschrift, pp. v.121, n. 5-6, p.228-238. SPRAWLS, P. J. (1993). Physical Principles of Medical Imaging. Gaithersburg: 2. ed. Aspen Publishers.

TAUHATA, L. S. (2003). Radioproteção e Dosimetria: Fundamentos. Rio de Janeiro: IRD/CNEN.

THRALL. (2010). Diagnóstico de Radiologia Veterinária. Rio de Janeiro: Elservier.

VEJA. (22 de julho de 2009). Eles Venceram. pp. p. 84-92.

VEJA-SP. (17 de outubro de 2012). Briga de cachorro grande. pp. pg. 52-63.

VENEZIANI, G. (2009). Avaliação das doses de cães submetidos a exames radiográficos de pulmão. Botucatu, SP.

VENEZIANI, G. R., MATSUSHIMA, L. C., FERNANDEZ, R. M., \& RODRIGUES, L. L. (28 de fevereiro de 2010). Thermoluminescence measurements of entrance surface skin dose in exams. Radiation Measurements, pp. v. 45, p. 733-735.

VUOLO, J. H. (1992). Fundamentos da teoria de erros. São Paulo: Edgard Blucher. 


\section{ANEXO}

Os exames radiográficos de tórax realizados em animais de grande porte estão apresentados na tabela 1:

Tabela 1: Dados referentes a exames de tórax para animais de grande porte.

\begin{tabular}{|c|c|c|c|c|c|c|c|c|}
\hline \multirow[b]{2}{*}{ EXAME } & \multirow[b]{2}{*}{ PORTE } & \multicolumn{2}{|c|}{ DIMENÕES } & \multirow[b]{2}{*}{$\mathrm{kV}$} & \multirow[b]{2}{*}{$\mathrm{mA}$} & \multirow[b]{2}{*}{$\mathrm{s}$} & \multirow[b]{2}{*}{ DFF } & \\
\hline & & $\mathrm{I}$ & I & & & & & \\
\hline \multirow[t]{2}{*}{1} & Grande & 21 & 50 & 74 & 300 & 0,06 & 1,15 & LL \\
\hline & & 18 & 32 & 70 & 300 & 0,06 & 1,15 & $\mathrm{LL}$ \\
\hline \multirow[t]{2}{*}{2} & Grande & 18 & 32 & 74 & 300 & 0,06 & 1,15 & VD \\
\hline & & 18 & 32 & 74 & 300 & 0,06 & 1,15 & VD \\
\hline 3 & Grande & 17,5 & 34 & 66 & 300 & 0,04 & 1,15 & $\mathrm{LL}$ \\
\hline
\end{tabular}

Os exames radiográficos de tórax realizados em animais de médio porte estão apresentados na tabela 2:

Tabela 2: Dados referentes a exames de tórax para animais de médio porte.

\begin{tabular}{|c|c|c|c|c|c|c|c|c|}
\hline \multirow{2}{*}{ EXAME } & \multirow{2}{*}{ PORTE } & \multicolumn{2}{|c|}{ DIMENÕES } & \multirow{2}{*}{$\mathrm{kV}$} & \multirow{2}{*}{$\mathrm{mA}$} & \multirow{2}{*}{$\mathrm{s}$} & \multirow{2}{*}{ DFF } & \\
\hline & & LL & VD & & & & & \\
\hline \multirow{3}{*}{1} & \multirow{3}{*}{ Médio } & 13 & 15 & 56 & 300 & 0,04 & 1,15 & LL \\
\hline & & & & & & & & \\
\hline & & 13 & 15 & 57 & 300 & 0,04 & 1,15 & LL \\
\hline \multirow{3}{*}{2} & \multirow{3}{*}{ Médio } & 14 & 18 & 59 & 300 & 0,04 & 1,15 & LL \\
\hline & & & & & & & & \\
\hline & & 12 & 16 & 56 & 300 & 0,04 & 1,15 & LL \\
\hline \multirow{3}{*}{3} & \multirow{3}{*}{ Médio } & 12,5 & 14 & 55 & 300 & 0,02 & 1,15 & LL \\
\hline & & & & & & & & \\
\hline & & 12,5 & 14 & 58 & 300 & 0,04 & 1,15 & VD \\
\hline \multirow{3}{*}{4} & \multirow{3}{*}{ Médio } & 11 & 14 & 60 & 300 & 0,04 & 1,15 & LL \\
\hline & & & & & & & & \\
\hline & & 11 & 14 & 62 & 300 & 0,04 & 1,15 & VD \\
\hline 5 & Médio & 12 & 15 & 59 & 300 & 0,04 & 1,15 & LL \\
\hline
\end{tabular}




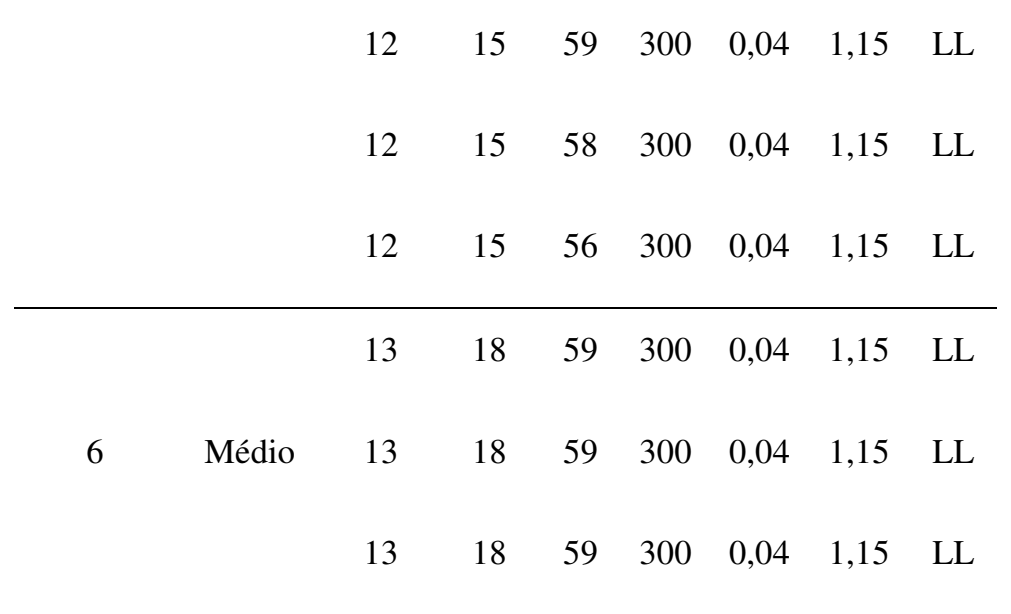

Os exames radiográficos de tórax realizados em animais de pequeno porte estão apresentados na tabela 3:

Tabela 3: Dados referentes a exames de tórax para animais de pequeno porte.

\begin{tabular}{|c|c|c|c|c|c|c|c|c|}
\hline \multirow[b]{2}{*}{ EXAME } & \multirow[b]{2}{*}{ PORTE } & \multicolumn{2}{|c|}{ DIMENÕES } & \multirow[b]{2}{*}{$\mathrm{kV}$} & \multirow[b]{2}{*}{$\mathrm{mA}$} & \multirow[b]{2}{*}{$\mathrm{s}$} & \multirow[b]{2}{*}{ DFF } & \\
\hline & & $\mathrm{U}$ & VD & & & & & \\
\hline \multirow{3}{*}{1} & \multirow{3}{*}{ Pequeno } & 10 & 11 & 54 & 300 & 0,04 & 1,15 & LL \\
\hline & & & & & & & & \\
\hline & & 10 & 11 & 56 & 300 & 0,04 & 1,15 & LL \\
\hline \multirow{3}{*}{2} & \multirow{3}{*}{ Pequeno } & 10 & 13 & 60 & 300 & 0,04 & 1,15 & LL \\
\hline & & & & & & & & \\
\hline & & 10 & 13 & 60 & 300 & 0,04 & 1,15 & LL \\
\hline \multirow{5}{*}{3} & \multirow{5}{*}{ Pequeno } & 9,5 & 12 & 62 & 300 & 0,04 & 1,15 & LL \\
\hline & & 9,5 & 12 & 60 & 300 & 0,04 & 1,15 & LL \\
\hline & & & & & & & & \\
\hline & & 9,5 & 12 & 60 & 300 & 0,04 & 1,15 & LL \\
\hline & & 9,5 & 12 & 58 & 300 & 0,04 & 1,15 & LL \\
\hline \multirow{3}{*}{4} & \multirow{3}{*}{ Pequeno } & 11 & 11 & 54 & 300 & 0,04 & 1,15 & LL \\
\hline & & & & & & & & \\
\hline & & 11 & 11 & 54 & 300 & 0,04 & 1,15 & LL \\
\hline
\end{tabular}

Os exames radiográficos de abdômen realizados em animais de médio porte estão apresentados na tabela 4.

Tabela 4: Dados referentes a exames de abdômen de animais de médio porte.

EXAME PORTE $\frac{2}{\mathrm{LL} \quad \mathrm{VD}} \mathrm{kV} \quad \mathrm{mA} \quad \mathrm{s} \quad \mathrm{DFF}$




\begin{tabular}{|c|c|c|c|c|c|c|c|c|}
\hline 1 & Médio & 15,5 & 21 & 58 & 200 & 0,08 & 1,00 & LL \\
\hline \multirow[t]{2}{*}{2} & Médio & 13 & 15 & 58 & 200 & 0,06 & 1,00 & LL \\
\hline & & 12 & 15 & 54 & 200 & 0,08 & 1,00 & LL \\
\hline \multirow[t]{2}{*}{3} & Médio & 12 & 15 & 54 & 200 & 0,08 & 1,00 & LL \\
\hline & & 12 & 15 & 54 & 200 & 0,08 & 1,00 & LL \\
\hline \multirow[t]{2}{*}{4} & Médio & 12 & 20 & 56 & 200 & 0,08 & 1,00 & LL \\
\hline & & 15 & 19 & 67 & 200 & 0,06 & 1,00 & LL \\
\hline \multirow[t]{2}{*}{5} & Médio & 15 & 19 & 70 & 200 & 0,06 & 1,00 & VD \\
\hline & & 15 & 19 & 72 & 200 & 0,06 & 1,00 & VD \\
\hline
\end{tabular}

Os exames radiográficos de abdômen realizados em animais de pequeno porte estão apresentados na tabela 5 .

Tabela 5: Dados referentes a exames de abdômen de animais de pequeno porte.

\begin{tabular}{cccccccccc}
\hline & & \multicolumn{3}{c}{ DIMENÕES } & & & & \\
\cline { 3 - 6 } EXAME & PORTE & & \multicolumn{3}{c}{$\mathrm{kV}$} & $\mathrm{mA}$ & $\mathrm{s}$ & $\mathrm{DFF}$ & \\
& & & & & & & & \\
\hline 1 & Pequeno & 10 & 13 & 55 & 200 & 0,06 & 1,00 & $\mathrm{LL}$ \\
\hline 2 & Pequeno & 10 & 22 & 58 & 200 & 0,08 & 1,00 & $\mathrm{LL}$ \\
\hline 3 & Pequeno & 11 & 13 & 52 & 200 & 0,08 & 1,00 & $\mathrm{LL}$ \\
\hline 4 & Pequeno & 8,5 & 9 & 58 & 200 & 0,06 & 1,00 & $\mathrm{LL}$ \\
\hline 5 & Pequeno & & & & & & & \\
\hline & & 11,5 & & 60 & 200 & 0,08 & 1,00 & $\mathrm{LL}$ \\
\hline
\end{tabular}

O exame radiográfico de abdômen realizado em animal de grande está apresentado na tabela 6.

Tabela 6. Dado referente a exame de abdômen de animal de grande porte

\begin{tabular}{ccccccccc}
\hline \multirow{2}{*}{ EXAME } & PORTE & \multicolumn{2}{c}{ DIMENÕES } & & & & \\
\cline { 3 - 7 } & & LL & VD & & & & & \\
& & 22 & & 78 & 200 & 0,08 & 1,00 & LL \\
\hline \multirow{2}{*}{1} & Grande & & & & & & & \\
& & 22 & & 75 & 200 & 0,08 & 1,00 & LL \\
\hline
\end{tabular}

